University of Louisville

ThinkIR: The University of Louisville's Institutional Repository

Electronic Theses and Dissertations

$5-2010$

\title{
3D CBCT analysis of cranial base morphology and its relationship to skeletal malocclusion.
}

Russell M. Weaver 1973-

University of Louisville

Follow this and additional works at: https://ir.library.louisville.edu/etd

\section{Recommended Citation}

Weaver, Russell M. 1973-, "3D CBCT analysis of cranial base morphology and its relationship to skeletal malocclusion." (2010). Electronic Theses and Dissertations. Paper 1540.

https://doi.org/10.18297/etd/1540

This Master's Thesis is brought to you for free and open access by ThinkIR: The University of Louisville's Institutional Repository. It has been accepted for inclusion in Electronic Theses and Dissertations by an authorized administrator of ThinkIR: The University of Louisville's Institutional Repository. This title appears here courtesy of the author, who has retained all other copyrights. For more information, please contact thinkir@louisville.edu. 


\title{
3D CBCT ANALYSIS OF CRANIAL BASE MORPHOLOGY AND ITS RELATIONSHIP TO SKELETAL MALOCCLUSION
}

\author{
By \\ Russell M. Weaver \\ B.S. The College of William and Mary in Virginia, 2000 \\ D.D.S Virginia Commonwealth University School of Dentistry, 2004
}

\author{
A Thesis \\ Submitted to the Faculty of the \\ Graduate School of the University of Louisville \\ in Partial Fulfillment of the Requirements \\ for the Degree of \\ Masters of Science in Oral Biology \\ Department of Orthodontics and Pediatric Dentistry \\ University of Louisville \\ Louisville, KY
}

May 2010 


\title{
3D CBCT ANALYSIS OF CRANIAL BASE MORPHOLOGY AND ITS RELATIONSHIP TO SKELETAL MALOCCLUSION
}

\author{
By \\ Russell M. Weaver \\ B.S. The College of William and Mary in Virginia, 2000 \\ D.D.S Virginia Commonwealth University School of Dentistry, 2004
}

A Thesis Approved on

March 21, 2010

by the following Thesis Committee:

\footnotetext{
William C. Scarfe, BDS, FRACDS, Ms

Thesis Director

Alla G. Farman, BDS, PhD, DSc

Co-Thesis Director

Bruce Haskell, DMD, PhD

Púl Tiwana. DMD, MD
} 


\section{DEDICATION}

This thesis is dedicated to my wife, Jessica, whose undying love and support for me has sustained me through every minute of this effort. Without you I am lost. I also dedicate this thesis to my two beautiful little girls, Ainsley and Madison. Your daddy works so hard to give you the best life possible. 


\section{ACKNOWLEDGMENTS}

I would like to offer my sincere thanks to all of the members of my thesis committee. Each of you has enriched my life with your contribution to this project. Dr. Scarfe, thank you for your constant open door. I am indebted to your free giving of time. Dr. Farman, thank you for keeping me on target. I look forward to a continued relationship with you both during my time developing CBCT protocols in the U.S. Army. Dr. Haskell, thank you for the many discussions, technical advice, and your immense vote of confidence in me. Dr. Tiwana, thank you for the original idea and the help in getting this project started so long ago. Your kind way and welcoming attitude has always been a reassuring part of this process. Finally, I would like to express my sincere thanks to the Graduate Dental education office of the U.S. Army for the opportunity to attend the University of Louisville and complete this degree program. 


\section{ABSTRACT \\ 3D CBCT ANALYSIS OF CRANIAL BASE MORPHOLOGY AND ITS RELATIONSHIP TO SKELETAL MALOCCLUSION}

Russell M. Weaver

March 31, 2010

Determining the etiology of skeletal malocclusion is an important diagnostic step in treatment planning patients with maxillofacial anomalies.

Aims: To describe cranial base morphology using cone beam computed tomography (CBCT) images and correlate with the Antero-posterior (AP) jaw discrepancy.

Methods: With IRB approval, retrospective analysis was performed on CBCT scans for 40 adult subjects. Cranial flexure and cranial deflection angle were analyzed in relation to three AP variables using linear regression analysis.

Results: There were no significant correlations between the cranial base and AP variables. This study can neither confirm that there is a correlation between the cranial base morphology and skeletal malocclusion nor definitively state that there isn't one.

Conclusions: Correlations on the sample between the cranial base and AP variables were unable to be determined. A prospective study design to control for more variables is recommended to further study the questions that remain unanswered from this study. 


\section{TABLE OF CONTENTS}

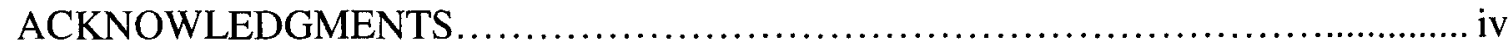

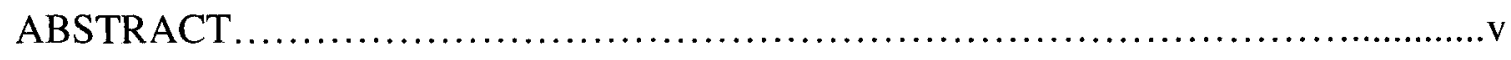

LIST OF TABLES ...............................................................

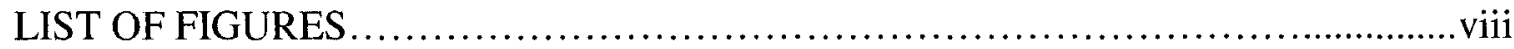

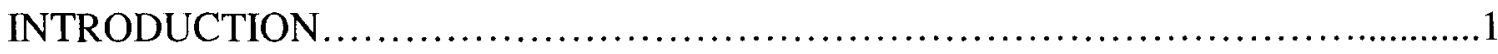

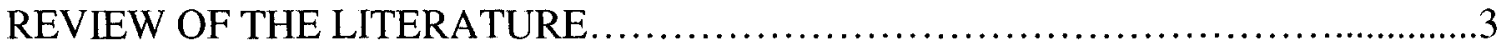

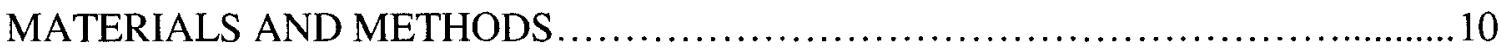

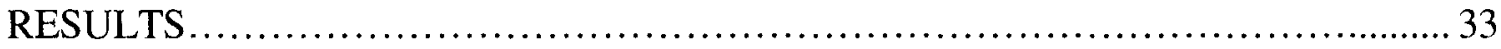

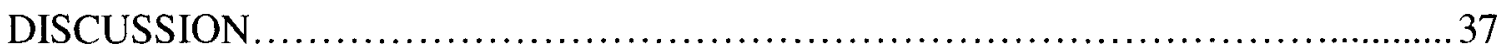

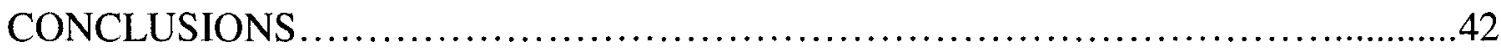

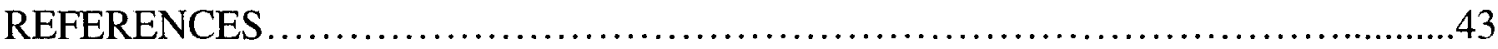

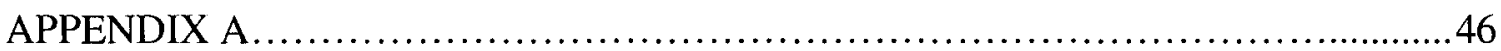

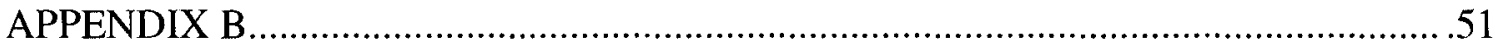

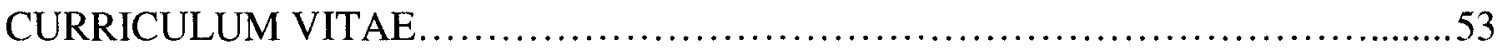




\section{LIST OF TABLES}

TABLE

PAGE

1. Midline \& bilateral topographic points used as landmarks for the measurements........14

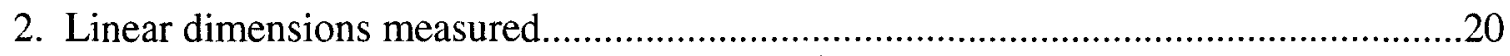

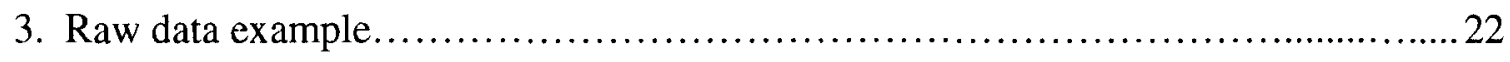

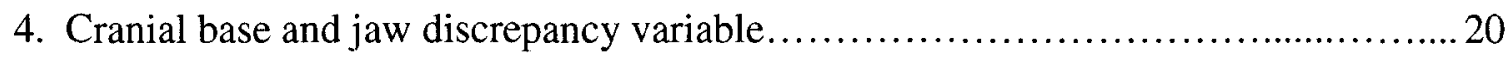

5. Mean values for horizontal jaw discrepancy \& cranial base descriptive parameters for

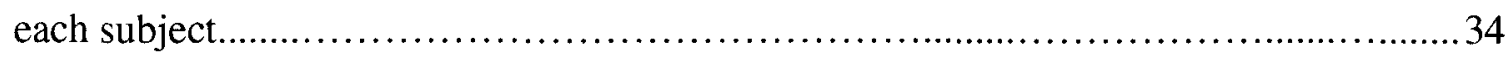

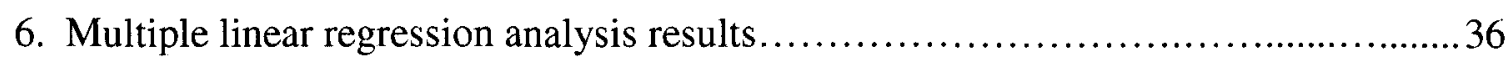

7. Linear regression analysis results for ANB / Cranial deflection ........................ 31

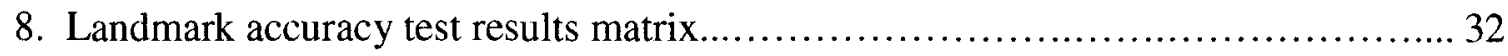




\section{LIST OF FIGURES}

FIGURE

PAGE

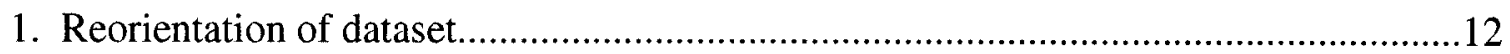

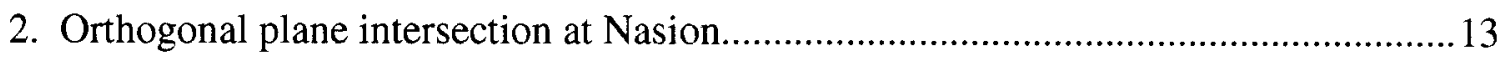

3. Nasion, A-point, and B-point ................................................. 15

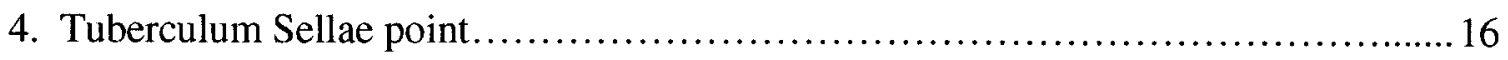

5. Glenoid Fossa point ............................................................ 17

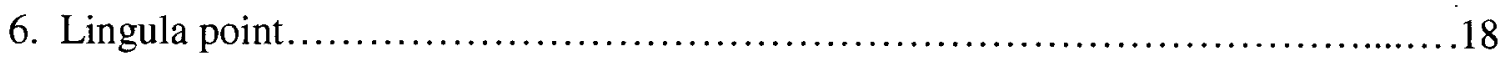

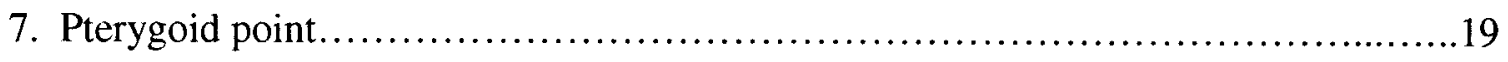

8. Calculation linear distance between $\mathrm{Na}$ to Ts representing the cranial base and ANB angle representing the maxilla-mandibular discrepancy.....................................21

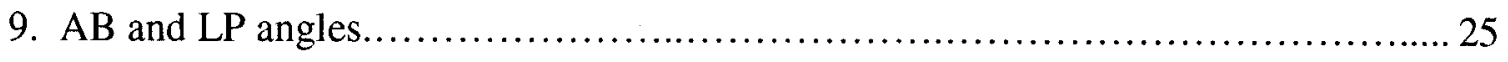

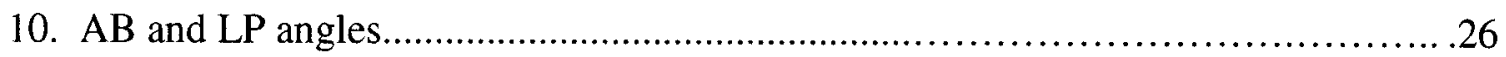

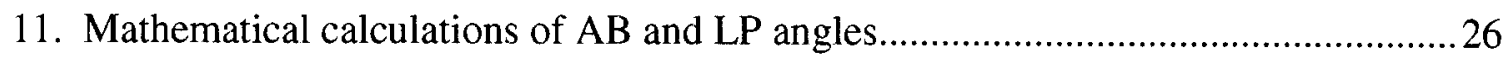

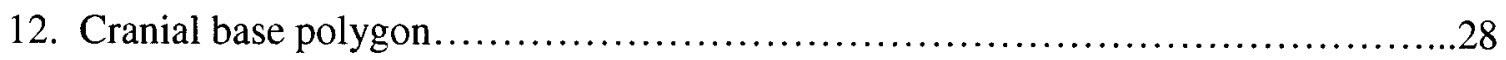

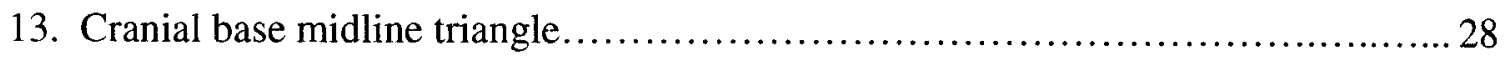

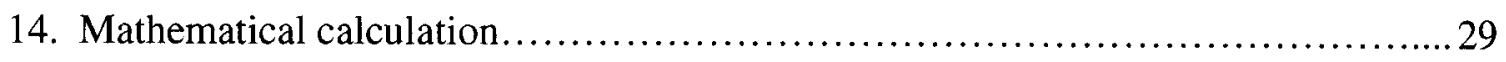

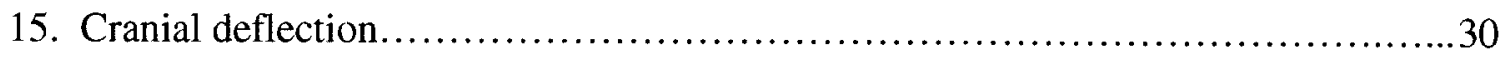

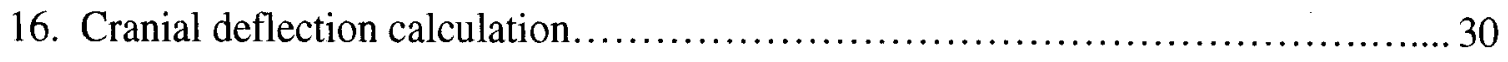




\section{INTRODUCTION}

The diagnostic process in orthodontics and maxillo-facial surgery requires identification of the underlying skeletal problems that contribute to dento-facial deformities and malocclusion. The clinical diagnosis significantly influences the treatment plan and can dictate the orthodontic mechanics used in a patient's treatment. It is therefore important to be able to establish the elements contributing to the etiology of the skeletal discrepancy. One of the key diagnostic skeletal relationships in the fields of orthodontics and maxillo-facial surgery is the anteroposterior $(\mathrm{A} / \mathrm{P})$ relationship of the maxilla to the mandible and their respective dentition. This relationship is affected by several factors including the size, form, and position of the jaws in space. In addition, it has been hypothesized that the morphology of the base of the cranium significantly contributes to the $\mathrm{A} / \mathrm{P}$ positions of the jaws and therefore impacts malocclusion. Until recently, viewing cranial base structures was limited to two dimensional radiographs such as lateral cephalometric and frontal images. There are limitations in this imaging approach due to the superimposition of structures that obscure detailed visualization. The introduction of Cone Beam Computed Tomography (CBCT) diagnostic imaging to these fields has the potential to provide more useful diagnostic information. CBCT has seen many clinical applications in dentistry, particularly in orthodontics and maxillofacial surgery. CBCT images can assist both orthodontists and surgeons in the diagnosis of dentofacial deformities, the detection of impacted teeth, as well as visualization of the 
three dimensional relationships of the jaws and the dentition. For decades orthodontists and oral surgeons have used conventional 2D radiographs in the evaluations, diagnoses, and treatment planning of their patients. In relation to lateral cephalomgrams, quantitative evaluation has been conducted using numerous cephalometric analyses developed and tested over the years. These analyses have been one of the primary tools for the orthodontist and surgeon. However as CBCT technology becomes more prevalent, 3D cephalometric analyses will be developed to provide information in all dimensions. This investigation is, in part, a step in that direction. The purpose of this study is to view the morphology of the cranial base in three dimensions using CBCT images in an attempt to better characterize the relationship between the shape of the cranial base and A/P skeletal malocclusion. 


\section{REVIEW OF THE LITERATURE}

\section{A. Measurement technique and accuracy on CBCT images.}

Before 3D cephalometric analyses can be realistically developed, the validity of measurement techniques utilized in the 3D environment must first be determined. Conventional 2D cephalometric analyses that have been utilized for years all share similar techniques. During the early years of cephalometric analysis development, the use of such techniques first required the confirmation that the measurements made on the radiograph were an accurate representation of the very real subject being analyzed. The same must be true for any 3D cephalometric analysis being developed.

As in conventional 2D cephalometric analysis, the first technical phase developing a 3D tracing is to place landmarks on identifiable anatomic locations. While this seems a trivial task, it becomes apparent to those who have attempted to do so that there are special challenges that do not exist in 2D tracing. The 2D cephalometric tracing simply requires that the clinician visualize structures on a static image. Conversely, measurements made on a 3D data set require constant manipulation of the images to locate landmarks accurately. There are three ways to place landmarks on the 3D data set. The first method is by viewing the data in the stack of $2 \mathrm{D}$ slices. The clinician typically has the ability to view the image in three planes and move seamlessly through each slice to locate the precise landmark visualized in each of the planes. The second method is to locate anatomic landmarks on a segmented volume rendered solid surface; i.e. imported 
digital models for example. The final method requires the location of the landmarks on the rendered 3D image. There is a fourth method as well that technically does not use a 3D image and involves merely deriving a conventional radiograph by compressing the 3D data set into a 2D image. The clinician could then perform any conventional 2D analysis of their choice. Numerous authors have reported on the accuracy of derived 2D images from 3D data. (Cattaneo et al. 2008, Kumar 2007, Moshiri, et al., 2007; Kumara et al. 2008) However, craniofacial measurement in a true 3D environment must utilize one of the first three methods. Multiple authors have reported on the accuracy and reproducibility of landmark identification on CBCT images (Cavalcanti et al. 2004, Muramatsu et al. 2008; Olszewski et al. 2008) while other have reported the accuracy of measurements made on 3D images. (Cavalcanti et al. 2004, Pinsky et al. 2006, Brown et al. 2009, Lascala et al. 2004, Stratemann et al. 2008, Ballrick et al. 2008, Periago et al. 2008) Grauer, Cevidanes, and Proffit (2009) recently surveyed the current literature on the subject and summarized as follows:

Studies from [method 1] report good accuracy regardless of where the measurements were made. For most measurements, there were no statistically significant differences compared with the gold standard (measurements with a caliper or structures of known geometry). Some measurements had statistically significant differences, but those were small and not clinically significant. Studies from [method 2] report subclinical accuracy when landmarks were located on segmentations or in the stack of slices but not when they were located on the rendered image. When all studies are considered regardless of their classification, reliability in measurements and landmark identification in CBCT images was reported to be good to very good. Based on the available evidence, we can conclude that it is more accurate to locate landmarks in the stack of slices or on a segmented surface. Landmarks located in the rendered volume must be carefully evaluated. (2009)

Clinical experience over the last two years with CBCT technology has led this author (RMW) to the same empiric conclusion. The clinician's ability to accurately locate reproducible landmarks on a rendered 3D image is dependent on many variables that affect the quality and usability of any scanned image. Defects on the rendered image 
such as scatter, surface holes, and difficulty in distinguishing surface features makes landmark identification extremely difficult and more inaccurate. Conversely, visualization of the data set in the $2 \mathrm{D}$ slice environment allows for relatively easy identification of landmarks in the style of conventional cephalometric tracing that most clinicians would find familiar. Simple on-screen tools allow the clinician to quickly slide between slices and place landmarks in any plane of space. Several studies have been conducted investigating the reliability and reproducibility of landmarks identification in the 2D slice environment vs. 3D rendered image environment. (Hassan et al. 2009, Oliveira et al. 2009, Grauer et al. 2009) It appears at this point that landmark identification in the 2D slice environment is simpler to accomplish and is more accurate than on the rendered 3D image. When using this technique, however, landmarks must be clearly defined as to their location in the three planes of space.

Angular measurements made in the 3D environment present another set of challenges that do not exist in the $2 \mathrm{D}$ cephalometric analysis. Since a conventional cephalometric tracing is made in two dimensions, it is simple to measure an angle between three landmarks or between two lines representing planes in two dimensions. The same simplicity cannot be said for measuring angles in 3D. 3D software programs do provide the clinician with the ability to calculate angles between three points in 3D space. There is, however, no way to measure angles between planes in 3D. The clinician must first determine a plane on which to project the lines to measure an angle. An example of this would be helpful at this point. Conventional lateral cephalometrics involves the evaluation of skeletal and dental relationships in an antero-posterior direction. To carry these relationships to the $3 \mathrm{D}$ analysis warrants the projection of 
angles to the mid-sagittal plane and visualized from the lateral vantage point. Therefore, the developments of 3D analyses that include angular measurements require detailed descriptions of how the angle is calculated including on which plane it is being projected and why. The literature provides little information on the accuracy of angular measurements made with 3D images. More research is needed to determine their accuracy. However, taking into consideration the current review of relevant literature it is reasonable to conclude that landmark identification reliability and linear measurements made on CBCT data sets are accurate enough to take the next step into 3D cephalometric analyses.

\section{B. Relationship of cranial base morphology and skeletal malocclusion}

According to Enlow (1990), the growth and development of the cranium has a direct impact on the position of the jaws. He theorized that as the flexure of the cranial base increased, i.e. as the angle formed between the anterior and middle cranial fossae decreased, the result would be a more prognathic position of the mandible and therefore an increased Class III tendency. Conversely, as the cranial base flexure decreased and the angle between the fossae increased, the result would be a more retrognathic position of the mandible and an increasing Class II tendency. Several studies have been conducted aimed at determining the contribution of the morphology of the cranial base to anteroposterior jaw position. Kerr, et al. (1988) concluded that cranial base size and shape influence mandibular prognathism by determining the anteroposterior position of the condyle relative to the facial profile. Andria, et al. (2004) determined that the posterior cranial base leg is the controlling factor in relating the cranial base to 
mandibular prognathism. Proff, et al. (2008) showed that decreased basi-cranial angulation was associated with Class III mandibular protrusion was clearly confirmed for skeletal Class III patients. Hopkin, et al. (1968) state that it is concluded that the dimensions of the cranial base are a major factor in determining $\mathrm{A} / \mathrm{P}$ relationships of the jaws and the dental arches which must be taken into account in diagnosis and treatment. Dibbets, et al. (1966) concluded in their study that the cranial base angle (Basion-SellaNasion) closed and the legs Sella-Nasion and Sella-Basion shortened systematically from Class II, over Class I, to Class III. Anderson and Popovich (1989) found that in normal and Class I malocclusions, the ramus and mandibular angles are found to correlate most strongly with cranial base dimensions rather than angles, whereas in Class II malocclusions these angles tend to relate more closely to the cranial base angles. They also used condylion as the posterior cranial base limit. However, there are several studies that could not conclude that the morphology of the cranial base could be strongly correlated to malocclusion. (Anderson, et al., 1983; Dhopatkar, et al., 2002; Polat, et al. 2007)

The results of these authors indicate that uncertainty remains on the influence of the cranial base on the etiology of malocclusion. There are several possible factors that contributed to the difficulties in linking skeletal malocclusion and cranial base anatomy. One factor is the contribution of jaw size discrepancy irrespective of cranial morphology. Another factor is that previous studies analyzed two dimensional lateral cephalometric radiographs with cranial base landmarks which were either a single midline structure (Sella, Nasion, and Basion), or a constructed landmark of superimposed structures (Articulare). While such studies do shed some light on the subject, they include inherent 
potential error in that they are comparing two dimensional structures on the cranial base to three dimensional bilateral structures of the jaws. The two dimensional landmarks have not been without merit though and to date have provided the best possible analysis in a two dimensional lateral cephalometric radiograph. The question currently is whether these commonly used two dimensional landmarks provide us with the best option since they may not accurately represent where the jaws meet the cranial base. As stated above, the anatomic connection between the jaws and the base of the cranium is not a two dimensional relationship. The use of Articulare as the posterior limit of the cranial base attempts to include the third (transverse) dimension but still includes the superimposition of the skull base medial to the rami. Anderson and Popovitch (1989) attempted to overcome this by showing that there was merit in using condylion as the posterior limit of the cranial base. However, condylion can be a difficult landmark to locate except on the clearest of $2 \mathrm{D}$ images.

\section{Development of 3D cephalometric analyses}

With the advent of 3D CBCT imaging it is now possible to visualize and analyze the skull with much more clarity and in three dimensions. Using readily identifiable and reproducible landmarks, more realistic investigation can be conducted to determine the relationship between the cranial base and the $A / P$ positions of the jaws. There are, however, no widely accepted 3D cephalometric analyses available to utilize for this current investigation. Olszewski, et al. (2006) developed a prototype analysis (ACRO 3D) that is an attempt at converting a $2 \mathrm{D}$ analysis (Delaire analysis) into three dimensions. The authors claim that the ACRO 3D software is a user friendly technology 
that walks the user through point placement and automatically generates the analysis. Part of the analysis is the measurements of the cranial base anatomy. A more recent analysis was developed by Cho, et al (2009) and includes a very cursory inclusion of cranial base anatomy. Both analyses are first steps in bridging the gap between conventional 2D lateral cephalometric analyses and new 3D analyses. However, neither provided the tools necessary to carry out this current investigation.

\section{Study Aims}

The purpose of this study was to describe cranial base morphology and its potential relationship to the position of the jaws using new 3D craniofacial landmarks identified on 3D volume renderings derived from CBCT datasets. New landmarks were chosen in an attempt to more accurately represent the cranial base as well as the A/P relationship of the jaws to each other. The intention was to characterize the cranial base where the "rubber meets the road". Therefore new landmarks were chosen in the glenoid fossa as the posterior limit of the cranial base where it meets the mandible. The A/P jaw relationship was also defined differently. The conventionally used ANB angle was included as the basis for relating the maxilla to the mandible. Because ANB has known limitations in accurately identifying skeletal malocclusion, an attempt was made to develop a new method of representing the A/P relationship of the maxilla to the mandible using information contained in the 3D CBCT image. Therefore the maxilla was compared to the mandible at both the anterior and posterior limits. Relating the jaws at their posterior limits was included in an attempt to eliminate the un-controlled variable of jaw size as a contributing factor in malocclusion. While jaw size is an inherent and important factor in the etiology of malocclusion the intent of this study was to identify 
the cranial base contribution to malocclusion regardless of jaw size. Landmarks were chosen at the pterygoid plates on the posterior of the maxilla as well as on the Lingula of the mandible to accomplish this posterior relationship measurement. A thorough description of landmark identification as well as the analysis follows in the Materials and Methods section. 


\section{MATERIALS AND METHODS}

\section{Hypotheses and alternative hypotheses}

It is hypothesized that there will be a significant positive correlation between cranial flexure and $\mathrm{A} / \mathrm{P}$ jaw position. As cranial flexure angle increases, so will the angles used to measure the $\mathrm{A} / \mathrm{P}$ position of the jaws. It is also hypothesized that we will observe a significant but negative correlation between cranial deflection and $\mathrm{A} / \mathrm{P}$ jaw position. As the cranial deflection angle increases the angles used to measure the $A / P$ position of the jaws will decrease. Finally, it is hypothesized that the combination of cranial flexure and deflection together will correlate stronger with the $\mathrm{A} / \mathrm{P}$ jaw position variables than each of the cranial base variables taken in isolation.

\section{Subjects}

The sample consisted of forty (40) CBCT datasets of patients who had presented for diagnostic imaging at the University of Louisville School of Dentistry radiology department. Institutional review board (IRB) approval was obtained to retrospectively review patient records in the CBCT database; IRB number 10.0165. Inclusion criteria included subjects who were at least 18 years old with full head scans including Nasion superiorly, right and left Porion posteriorly, the entire mandible inferiorly and all facial structures anteriorly. Selected subjects were also required to have teeth together in apparent maximum intercuspation with enough posterior teeth to allow for a stable vertical stop. Selected subjects ranged from 18 to 67 years old with a mean age of 49 
years old. 18 males and 22 females were selected. No attempt was made to select for sex, race or ethnicity. Subjects were excluded if there was obvious evidence of facial surgery or if the image quality did not allow for proper landmark identification.

\section{Imaging}

All CBCT datasets were acquired using the i-CAT CBCT unit (Danaher/Imaging Sciences International, Hatfield, PA, USA). The device was operated at $1-3 \mathrm{~mA}$ and 120 $\mathrm{kV}$ using a high frequency, constant potential, and fixed anode with a nominal focal spot size of $0.5 \mathrm{~mm}$. Each patient was positioned into the device supported by the constructed plastic head holder. The chin of each subject was inserted into the chin holder and vertical and horizontal laser lights on the device used to position the head. Attempts were made such that the head was oriented with the mid-sagittal perpendicular to the floor and the horizontal laser reference was along an imaginary line at the intersection of the posterior maxillary teeth and alveolar ridge. Lateral scout radiographs were then taken to ensure that the entire maxillofacial skeleton was within the field of view of the acquired dataset. "Full" field of view $(17 \mathrm{~cm}$ (diameter) x $13.2 \mathrm{~cm}$ (height)) scans of each patient were then taken usually at a 20second exposure 360 degree scan comprising 306 projections. Primary reconstruction of the data was performed immediately after acquisition.

The original for presentation DICOM data of the selected subject was first imported into Dolphin 3D (Dolphin Imaging, Chatsworth, CA.) for analysis. Each dataset was then re-oriented (Figure 1). From the frontal view the dataset was oriented with right and left Orbitale level with the axial plane. Each image was then oriented with the skull in as close to a straight on view as possible. This was accomplished by placing 
the sagittal reference plane line on Nasion and rotating the image left or right until the bilateral structures of the skull were even on both sides. Next the image was oriented with right side Porion and Orbitale (Frankfort horizontal) parallel to the floor. With the image now oriented the three reference lines (Sagittal, Axial, Coronal) were then moved to all intersect at Nasion (Figure 2). The effect of this in Dolphin 3D places the origin of the $\mathrm{x}, \mathrm{y}, \mathrm{z}$ coordinate system at Nasion.

Figure 1. Reorientation of Dataset

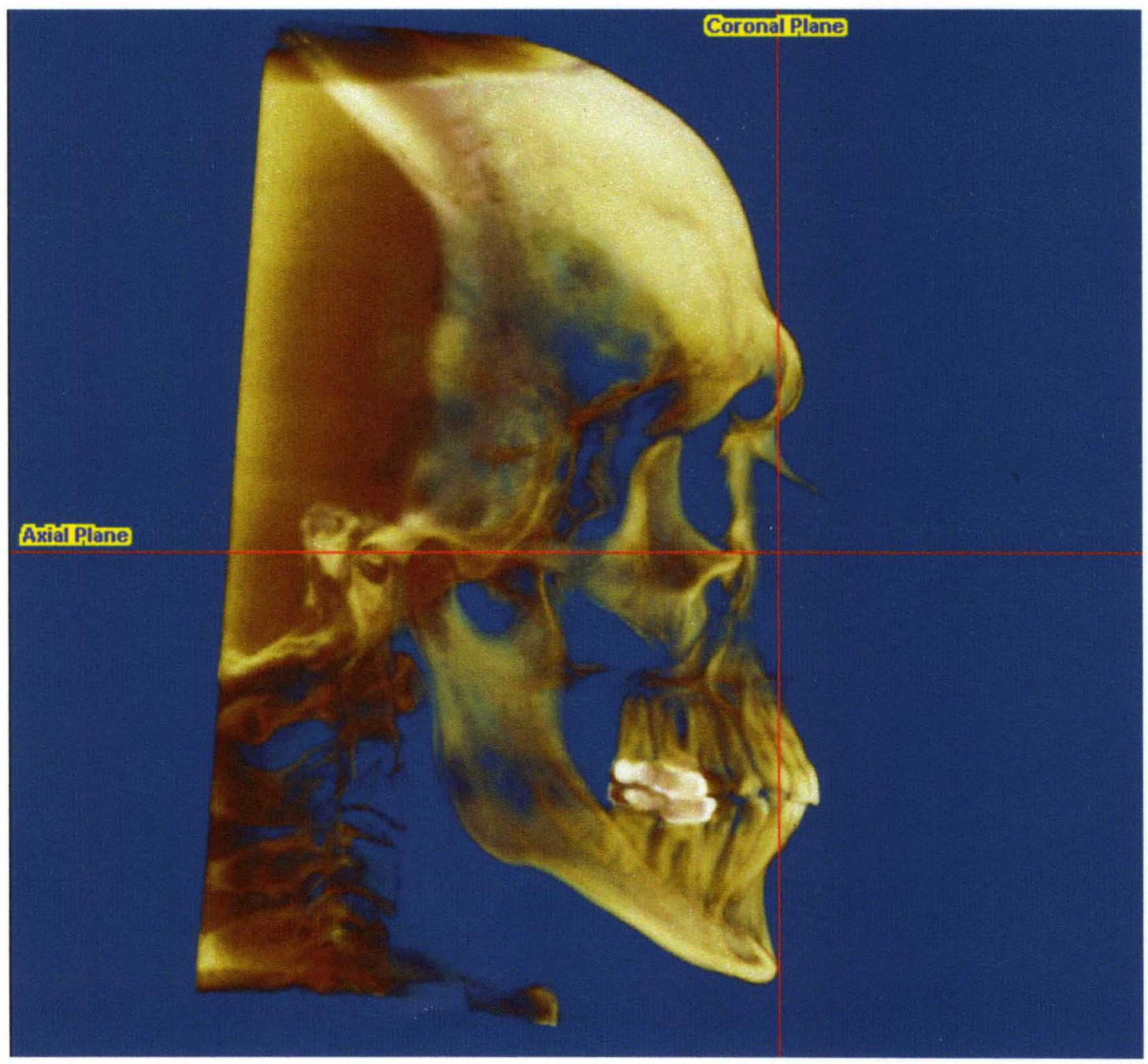


Figure 2. Orthogonal plane intersection at Nasion

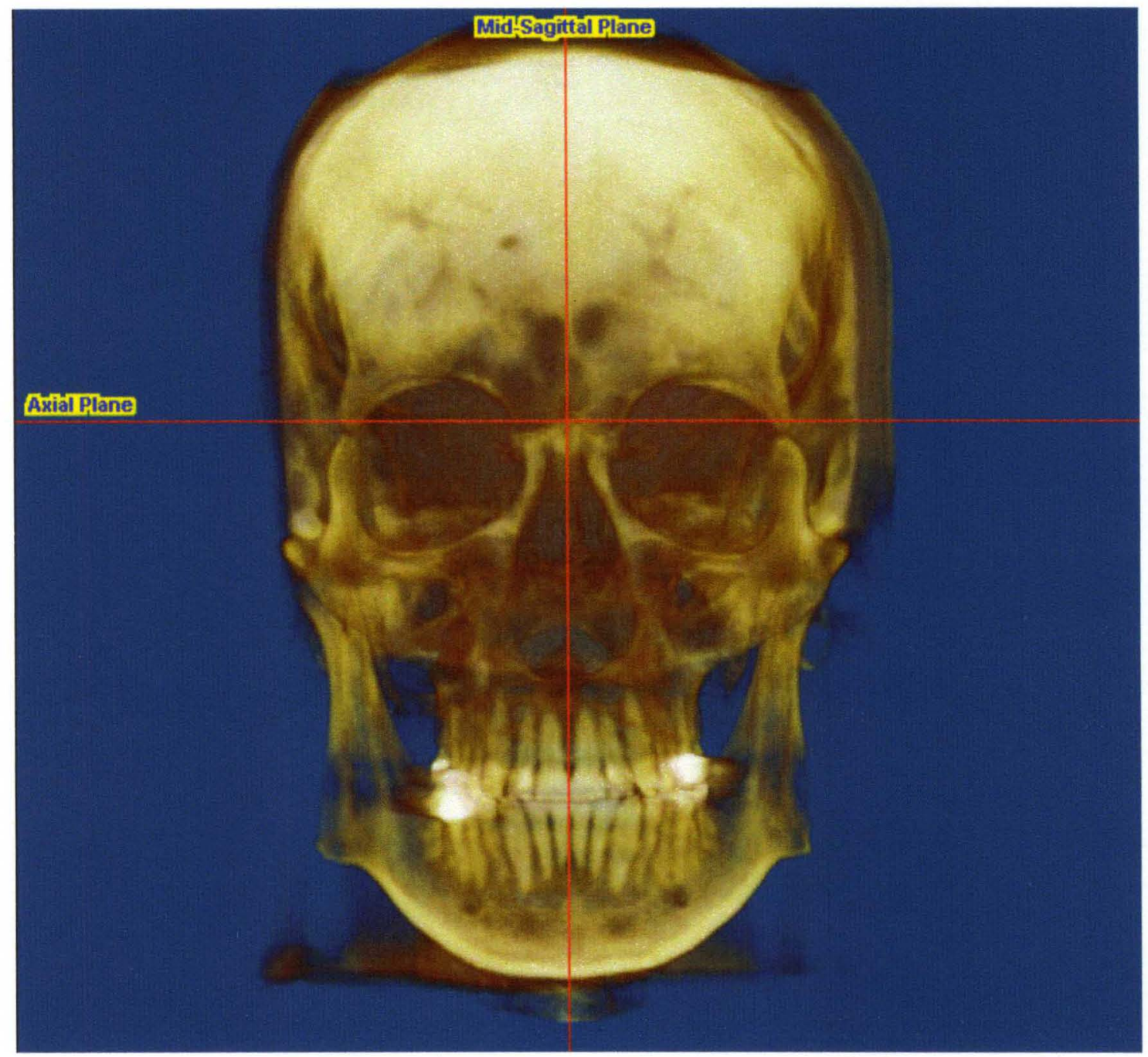

Once the re-orientation of the dataset was complete, 3D cephalometric the "tracing" was performed. Ten landmarks were identified (Table 1). Each landmark was identified using the $2 \mathrm{D}$ slice windows in Dolphin 3D. The $2 \mathrm{D}$ slice windows allowed for simple identification of structures in all three planes of space. (Figures 3-7) show how these points were identified using the imaging software. 
Table 1. Midline and Bilateral Topographic Points Used as Landmarks for the Measurements

\begin{tabular}{|c|c|c|}
\hline Landmark & Abbreviation & Definition / Derivation \\
\hline \multicolumn{3}{|l|}{ MID-LINE } \\
\hline B Point & B & $\begin{array}{l}\text { The posterior most point between pogonion and the } \\
\text { crest of the labial plate on the mid-sagittal plane. } \\
\text { (Fig. 3) }\end{array}$ \\
\hline $\begin{array}{l}\text { Tuberculum } \\
\text { sellae }\end{array}$ & Ts & $\begin{array}{l}\text { The most posterior superior point on the } \\
\text { Tuberculum Sellae located on the mid-sagittal } \\
\text { plane anterior to Sellae Turcica between the } \\
\text { Anterior Clinoid processes. (Fig. 4) }\end{array}$ \\
\hline Nasion & $\mathbf{N a}$ & $\begin{array}{l}\text { The anterior most point of the junction of the } \\
\text { frontal and nasal bones on the mid-sagittal plane. } \\
\text { When viewed in the sagittal plane it is seen as an } \\
\text { irregular notch. (Fig. 3) }\end{array}$ \\
\hline A Point & $\mathbf{A}$ & $\begin{array}{l}\text { The posterior most point on the innermost } \\
\text { curvature between the anterior nasal spine and the } \\
\text { crest of the labial alveolar plate. (Fig. } 3 \text { ) }\end{array}$ \\
\hline \multicolumn{3}{|l|}{ BILATERAL } \\
\hline Glenoid fossa & Gr / Gl & $\begin{array}{l}\text { The superior most point in the Glenoid Fossae in } \\
\text { both the Sagittal and Coronal planes. (Fig. 5) }\end{array}$ \\
\hline Lingula & $\mathbf{L r} / \mathbf{L l}$ & $\begin{array}{l}\text { The most posterior superior point on the Lingula } \\
\text { projection on the medial aspect of the mandibular } \\
\text { ramus. (Fig. } 6 \text { ) }\end{array}$ \\
\hline Pterygoid & $\mathbf{P r} / \mathbf{P I}$ & $\begin{array}{l}\text { Center most point on the junction of the pterygoid } \\
\text { plate and the right maxillary tuberosity at their } \\
\text { most inferior surface. (Fig. } 7 \text { ) }\end{array}$ \\
\hline
\end{tabular}


Figure 3. Nasion, A-Point, and B-Point.

Screen capture from Dolphin 3D (Dolphin Imaging, Chatsworth, CA.)
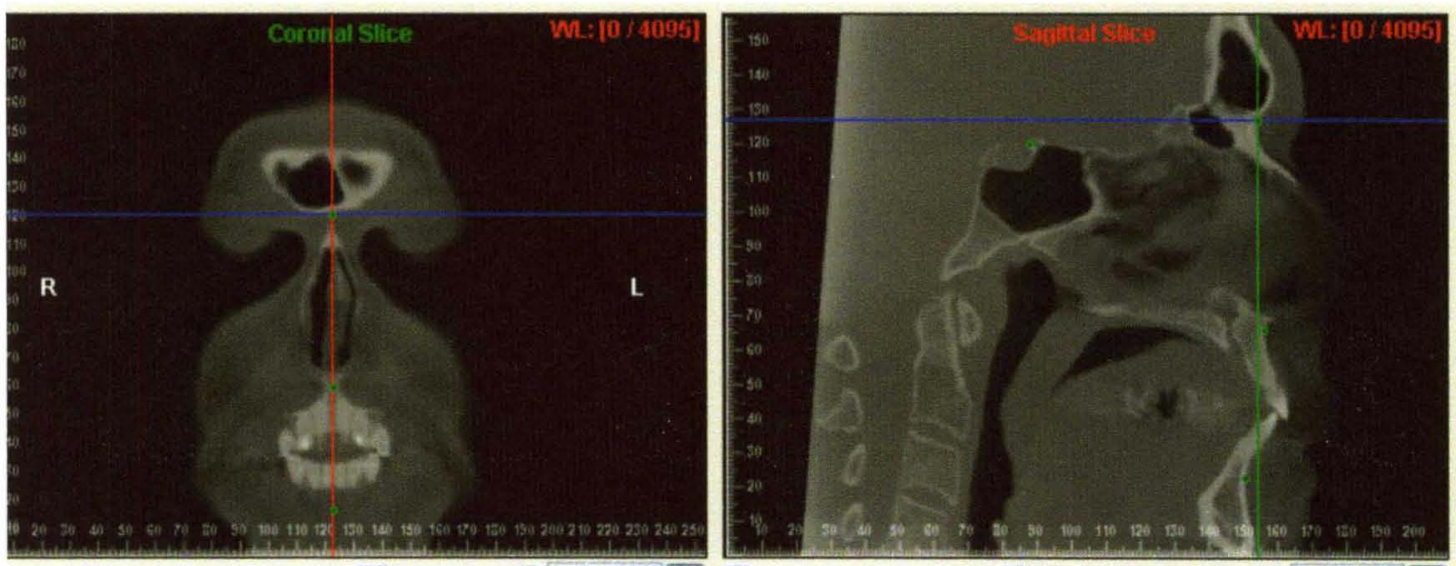

$>2.0 \mathrm{~mm} \vee W L$
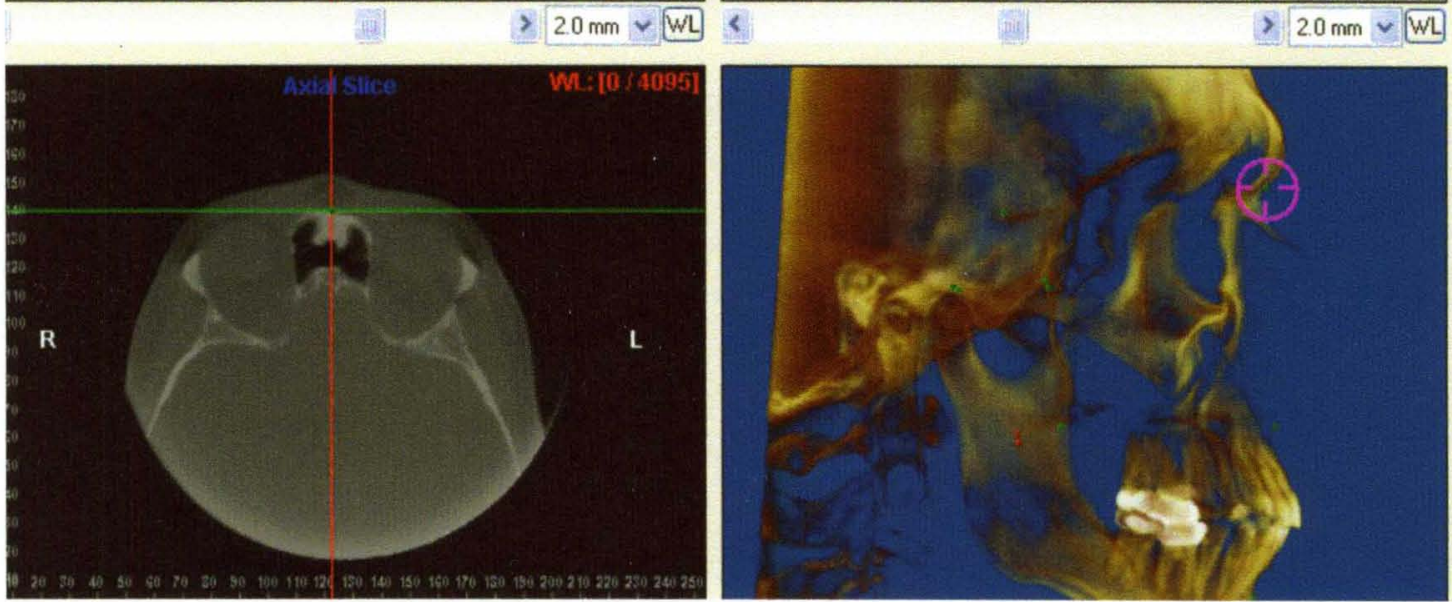
Figure 4. Tuberculum Sellae Point Screen capture from Dolphin 3D (Dolphin Imaging, Chatsworth, CA.)
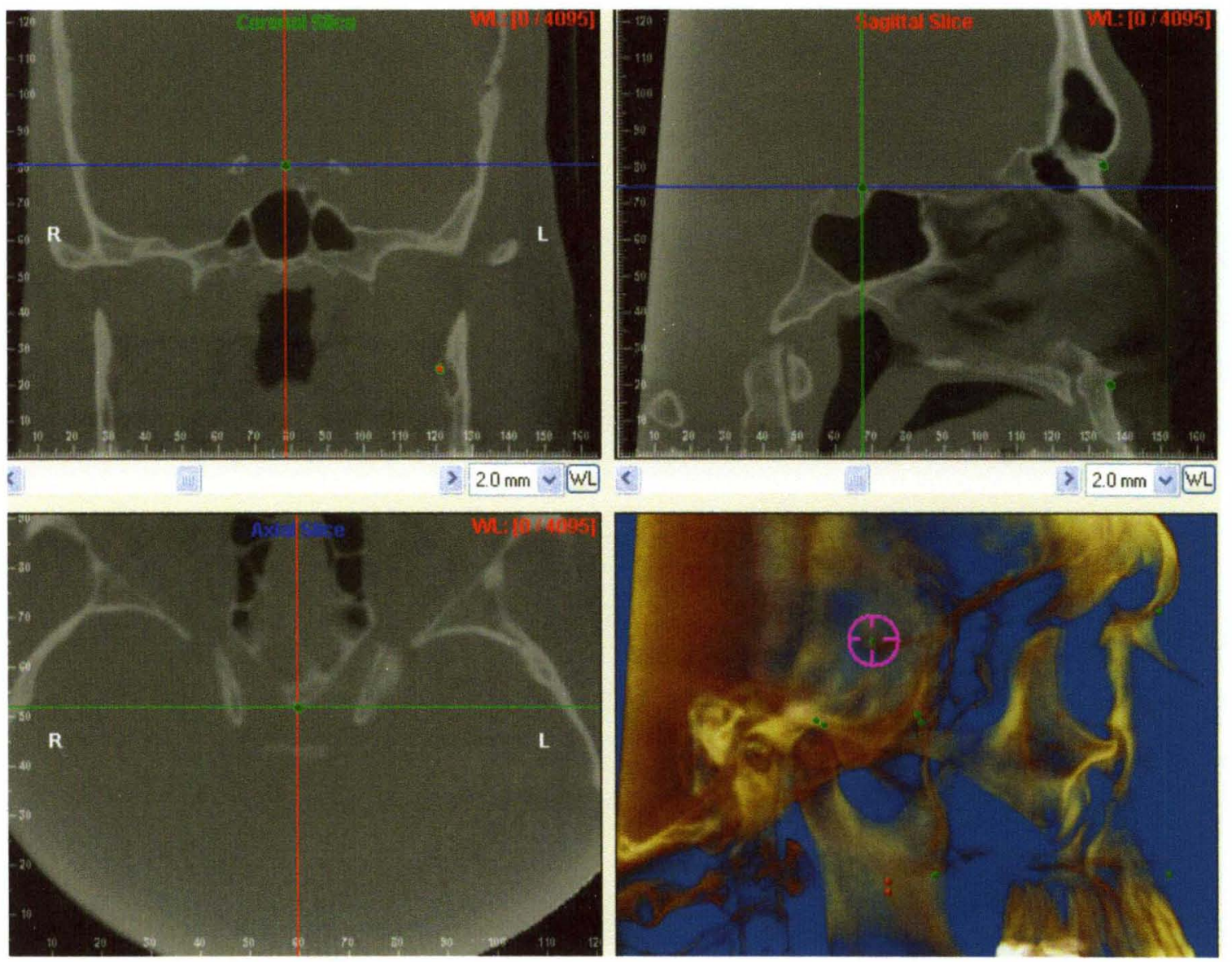
Figure 5. Glenoid Fossa Points (Right and Left)

Screen capture from Dolphin 3D (Dolphin Imaging, Chatsworth, CA.)

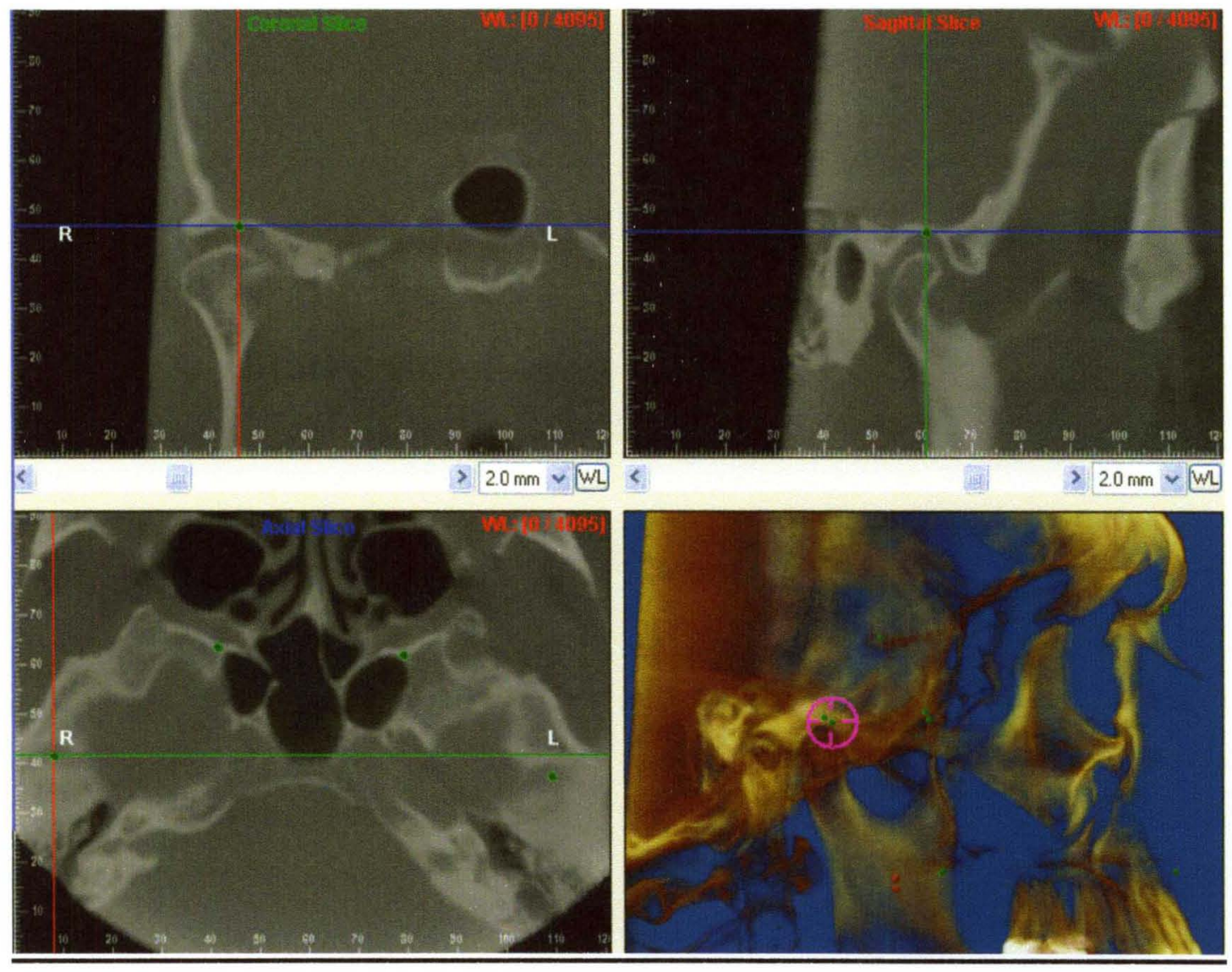


Figure 6. Lingula Points (Left and Right). Note: These two points were first placed using the rendered 3D image window on the lower right then adjusted using the Axial and Coronal slice windows to ensure the landmark was locate on the most posterior superior surface of the Lingula. Screen capture from Dolphin 3D (Dolphin Imaging, Chatsworth, CA.)
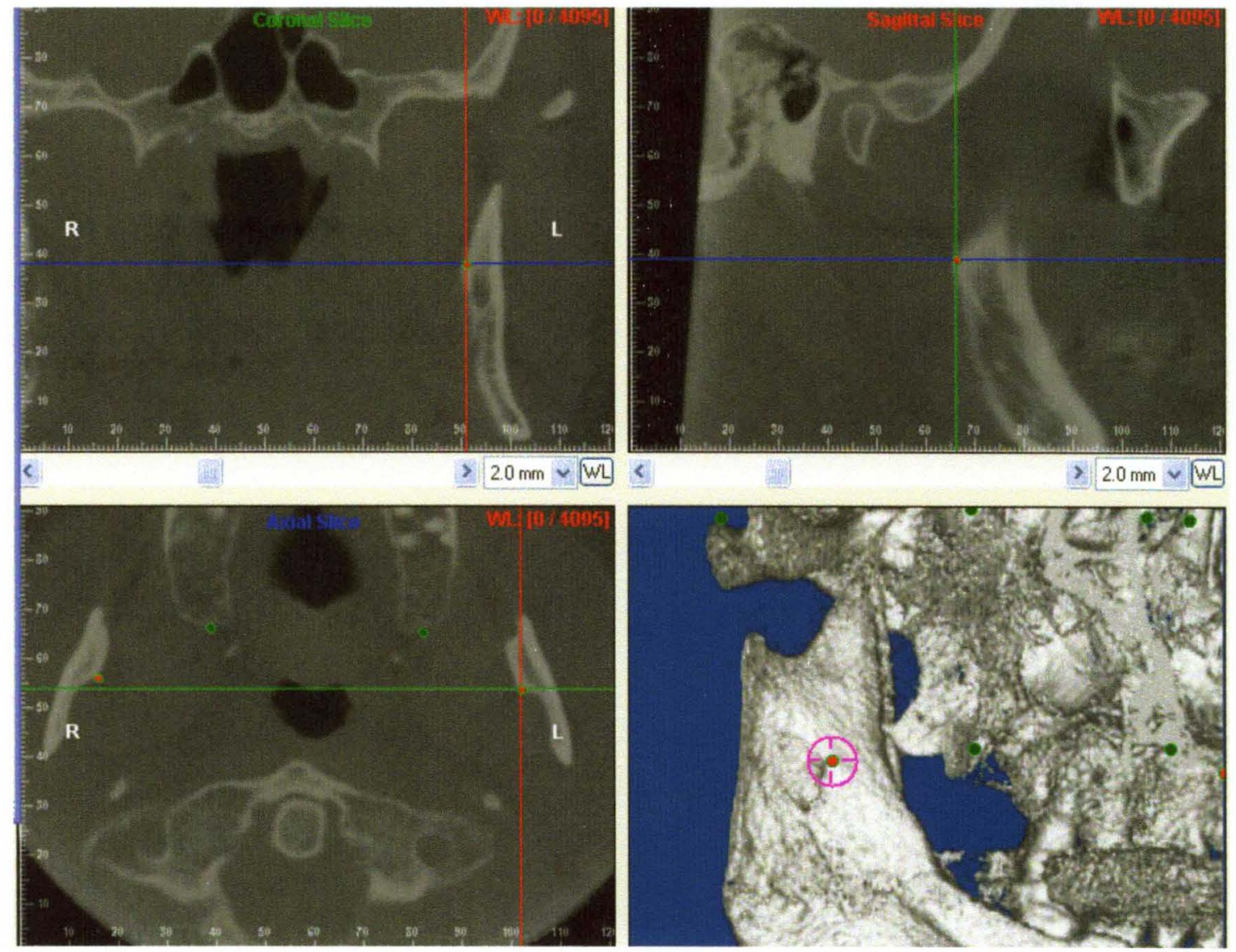
Figure 7. Pterygoid Points (Right and Left)

Screen capture from Dolphin 3D (Dolphin Imaging, Chatsworth, CA.)
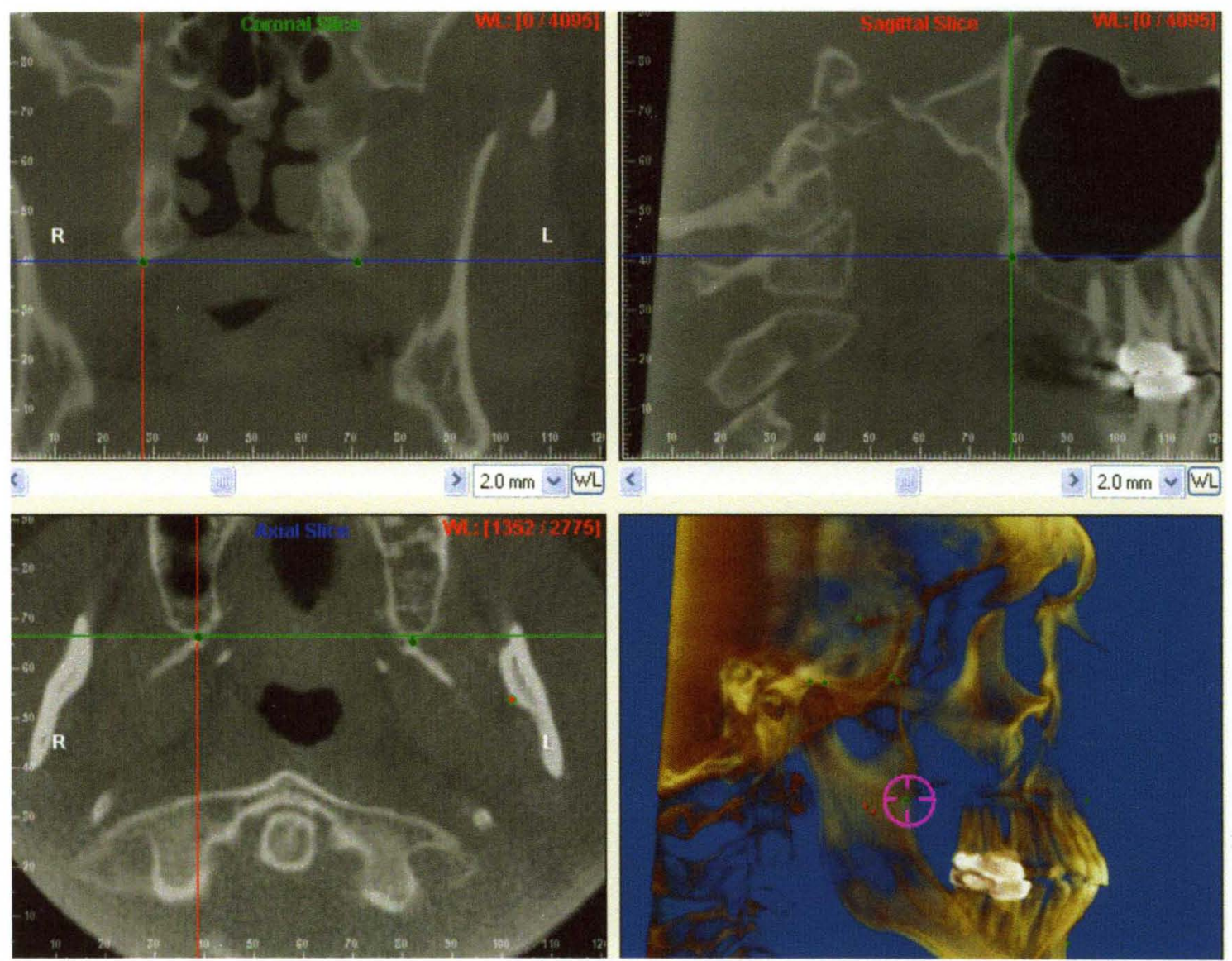
Two measurements (Table 2) characterizing the cranial base and maxillamandibular discrepancy of the maxillofacial skeleton were then measured directly on the 3D data set from a consideration of the following operational definitions. These measurements are not automatically performed by the landmark identification software. The user is required to switch from the landmark identification environment to the measurement environment. There are two operations that are available in the measurement environment. The user is able to measure a linear distance between two points or an angle between three points. The distance measurement is accomplished by marking the two points and then the software will record the distance between them in millimeters. The three point angle measurement is accomplished by marking the three points on the 3D data set and the software will calculate the angle in degrees to two decimal places at the second landmark. Figure 8 is an example of the measurement environment in the imaging software.

Table 2. Definitions of Angular and Linear Dimensions Measured

\begin{tabular}{lcl}
\hline Measurement & Abbreviation & Definition/Derivation \\
\hline $\begin{array}{l}\text { Nasion To Tubercullum } \\
\text { sella }\end{array}$ & Na-Ts & Linear distance in mm from Na to Ts. \\
$\begin{array}{lll}\text { A point to Nasion to B } \\
\text { point }\end{array}$ & ANB & $\begin{array}{l}\text { Three point angle measured from A-point to } \\
\text { Na to B-point. }\end{array}$ \\
\hline
\end{tabular}


Figure 8. Calculation of linear distance between Na to Ts representing the cranial based and ANB angle representing maxilla-mandibular discrepancy. Screen capture from Dolphin 3D (Dolphin Imaging, Chatsworth, CA.)

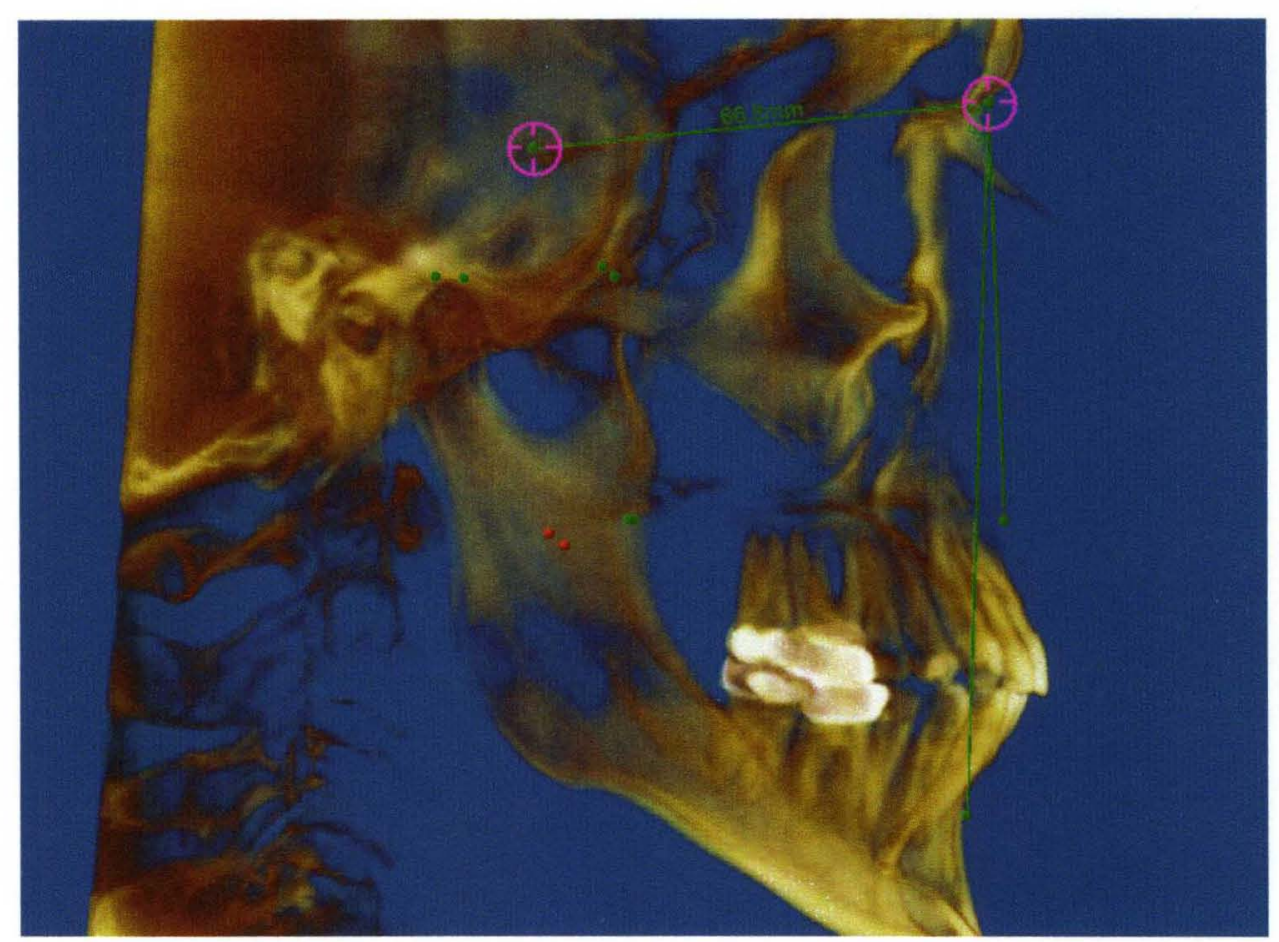

Once landmark identification was completed, the raw data was then exported to a spread sheet to facilitate calculations. Data exported included the $\mathrm{x}, \mathrm{y}, \mathrm{z}$ coordinates for each landmark placed as well as the linear distance and three point angle measurements made. Each of the landmark's coordinates was recorded as the mm distance from the $\mathrm{x}$, $\mathrm{y}, \mathrm{z}$ origin rounded to one decimal place. The $\mathrm{x}, \mathrm{y}, \mathrm{z}$ coordinate origin was set at Nasion during the orientation process. In Dolphin3D the transverse dimension is $\mathrm{x}$, the vertical dimension is $y$, and the anteroposterior dimension is z. Landmarks are positive if they are located to the left of the origin and negative if they are to the right. Landmarks are 
recorded as negative if they are located posterior to the origin and positive if they are anterior to the origin. Landmarks are recorded as negative if they are located inferior to the origin and positive if they are superior to the origin. An example of one subject's data is shown in Table 3.

Table 3. Example of Raw data for Patient 1 (Pnt1)

\begin{tabular}{lrrr}
\hline & Transverse & Vertical & AP \\
\hline & -- X-- & $--Y--$ & -- --- \\
\hline Landmark - 1 Nasion & 0 & 0 & 0.2 \\
Landmark - 2 A point & 0 & -60.8 & 2.2 \\
Landmark - 3 B point & 0 & -104.1 & -3.5 \\
Landmark - 4 TS point & 0 & -6.5 & -66.4 \\
Landmark - 5 Right G point & -51.6 & -25.6 & -76.6 \\
Landmark - 6 Left G point & 49.3 & -25.4 & -80.8 \\
Landmark - 7 Left L point & 42.1 & -62.7 & -64.3 \\
Landmark - 8 Right L point & -43.9 & -64.5 & -62.1 \\
Landmark - 9 Right P point & -21.2 & -60.8 & -51.9 \\
Landmark - 10 Left P point & 22.3 & -60.8 & -52.7 \\
2-Pt Distance mm - (N to Ts) & & & 66.8 \\
3-Pt Angle @ - 1 & & & 3.9 \\
\hline
\end{tabular}

The data for each subject was then used to calculate the 3D variables to be analyzed. Two variables (Cranial flexure and deflection) were selected to represent the morphology of the cranial base. Three variables (ANB, AB angle, and LP angle) were selected to represent the horizontal relationship of the Maxilla to the Mandible. The cranial base and jaw discrepancy variables are listed in Table 4 . 
Table 4. Cranial base and jaw discrepancy variables

\begin{tabular}{ll}
\hline Cranial base variable & \\
\hline Cranial flexure & $\begin{array}{l}\text { The angle formed between the lines from Na to Ts } \\
\text { point and Ts point to a point on the midsagittal plane } \\
\text { between right and left Glenoid fossa points } \mathrm{G}(\mathrm{mid}) . \\
\text { The angle formed between the line from Na to } \\
\text { G(mid) and the frankfort horizontal plane. }\end{array}$ \\
Horizontal jaw discrepancy variables & \\
ANB angle & $\begin{array}{l}\text { The angle formed between the lines from A point to } \\
\text { Na and Na to B point. } \\
\text { The angle formed between a line drawn from A point } \\
\text { to its perpendicular intersection with the superior } \\
\text { cranial base plane (SCBP) and a line drawn from B } \\
\text { point to the same intersection of the SCBP. } \\
\text { The angle formed between a line drawn from P(mid) } \\
\text { to its perpendicular intersection with the SCBP and a } \\
\text { line drawn from L(mid) to the same intersection of } \\
\text { the SCBP. }\end{array}$ \\
\hline
\end{tabular}

\section{Derivation of horizontal jaw discrepancy variables}

No attempt was made to select subjects and assign them to a treatment group such as class I, II, or III. Subjects were selected at random and chosen if they met the previously defined inclusion criteria. It was expected that the selected sample of subjects would represent the spectrum of jaw discrepancies. This spectrum of jaw discrepancy would be the basis of comparison to the spectrum of cranial base morphology being observed in the sample instead of distinct groups. Three angles were derived to represent the $\mathrm{A} / \mathrm{P}$ relationship of the maxilla to the mandible. The $\mathrm{ANB}$ and $\mathrm{AB}$ angles relate the jaws at their anterior limits while the LP angle relates the jaws at their posterior limits. 
1. ANB Angle (Figure 8). The ANB angle was measured directly on the CBCT image and was exported to the data spread sheet for each subject. Any student of cephalometrics knows the ANB angle can be a misleading measurement when taken in isolation. As an example, an individual with a class I skeletal relationship may still have a small to negative ANB angle if $\mathrm{Na}$ is positioned anteriorly in space due to a large Frontal sinus.

2. AB Angle (Figure 9 and 10). In an attempt to reduce the shortcomings of using the $\mathrm{ANB}$ angle, the $\mathrm{AB}$ angle was developed for this study as an alternative method. With the 3D image oriented with $\mathrm{FH}$ parallel to the floor and the subject's head in a nearly natural position, the horizontal discrepancy between the jaws is what is relevant to the profile. The discrepancy between A-point and B-point to each other regardless of $\mathrm{Na}$ is what we desired to observe. To calculate the $\mathrm{AB}$ angle, a line passing through $\mathrm{Na}$ parallel to $\mathrm{FH}$ was established. This line was called the superior cranial base plane (SCBP) line. A right triangle was constructed perpendicular to the SCBP line using the $y$ dimension (vertical) of B-point and the difference of the $z$ dimensions (horizontal) between $\mathrm{A}$ and $\mathrm{B}$ points. This places the apex of the angle on the SCBP directly superior to A-point in all subjects eliminating Na. The angle was derived mathematically as shown in (Figure 11).

3. LP angle (Figure 9 and 10). This angle was derived to represent and relate the posterior jaw limits, L-point to P-point, to each other. Due to the $\mathrm{x}$ dimension (transverse) of both $\mathrm{L}$ and $\mathrm{P}$ points it became necessary to construct the LP angle on the mid-sagittal plane. This was accomplished by taking the 
average $\mathrm{z}$ (horizontal) and $\mathrm{y}$ (vertical) dimensions of the bilateral landmarks with the $\mathrm{x}$ dimension (transverse) zeroed to the mid-sagittal plane to generate $\mathrm{L}$ (mid) and $\mathrm{P}(\mathrm{mid})$. The LP angle was then calculated using the same method as the $\mathrm{AB}$ angle. The legs of the right triangle were the $\mathrm{y}$ dimension (vertical) of $\mathrm{L}$ (mid) and the difference of the $\mathrm{z}$ dimensions (horizontal) between $\mathrm{L}$ (mid) and $\mathrm{P}$ (mid) points. The apex of the LP angle was located directly superior to $\mathrm{P}(\mathrm{mid})$ on the SCBP line on the mid-sagittal plane. The angle was derived mathematically as shown in (Figure 11).

Figure 9. $\mathrm{AB}$ and LP angles.

Screen capture from Dolphin 3D (Dolphin Imaging, Chatsworth, CA.)

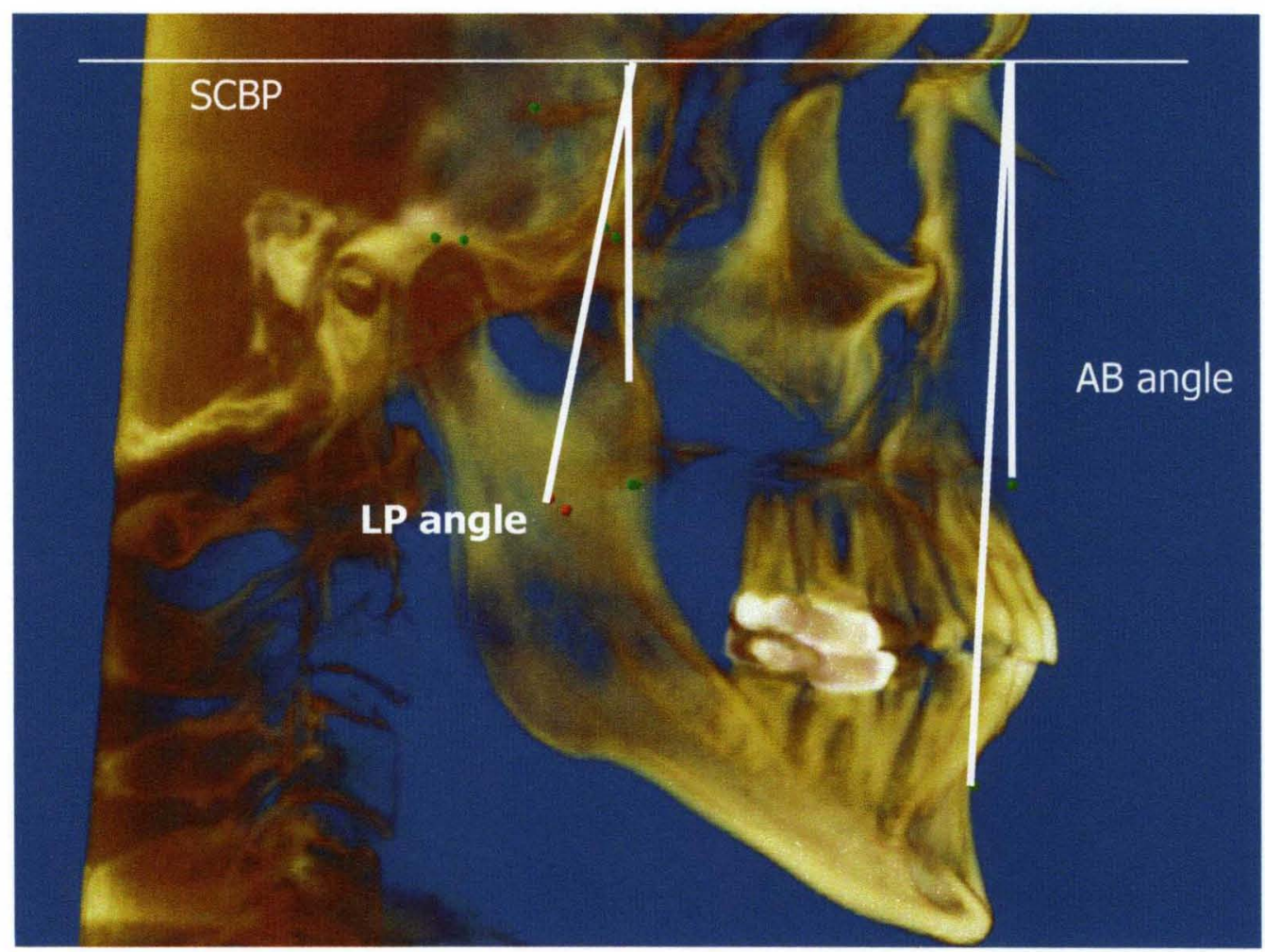


Figure 10. $\mathrm{AB}$ and $\mathrm{LP}$ angles

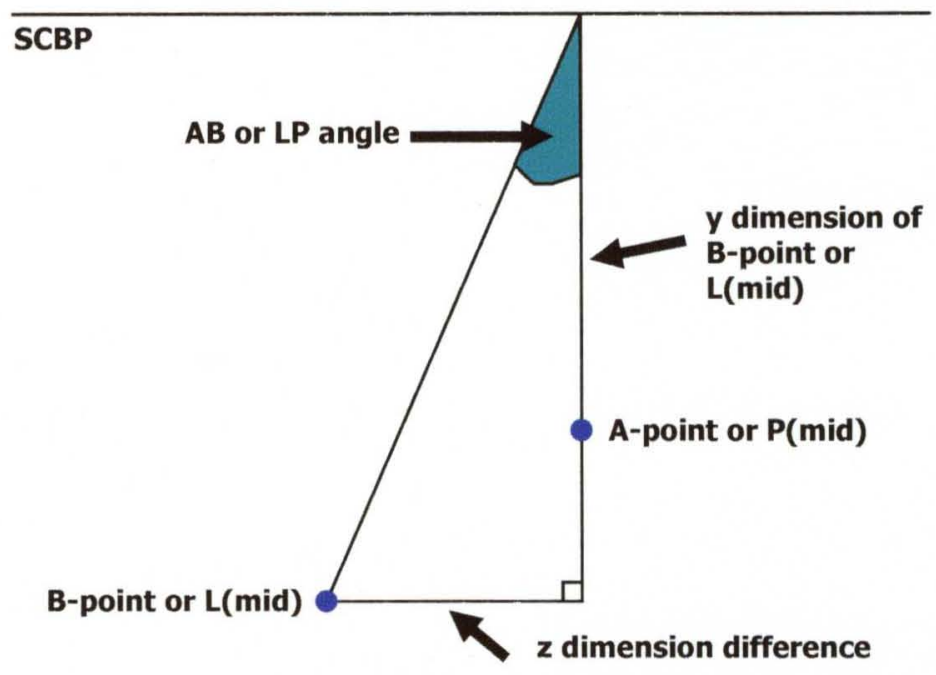

Figure 11. Mathematical calculation of AB and LP angles

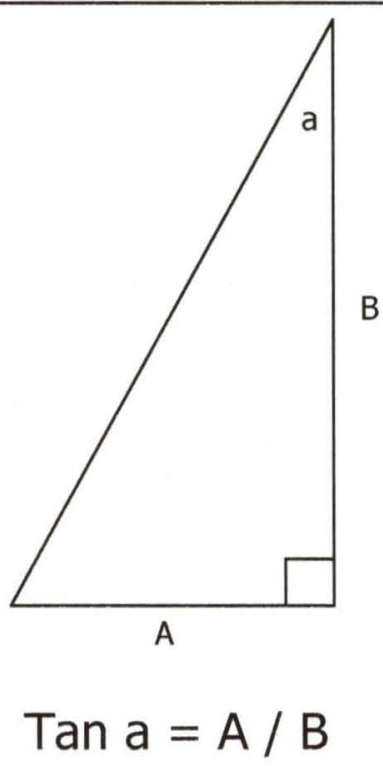




\section{Derivation of cranial base and cranial flexure measurement.}

To define cranial base and cranial flexure in 3D, the cranial base is represented by a three dimensional polygon with Nasion as the anterior limit and right and left G-points as the posterior limit. Ts-point completes the polygon at the flexure between the anterior and middle cranial fossae.

In this study the cranial flexure angle is calculated by projection to the midsagittal plane. Therefore cranial flexure is defined as the angle formed between the anterior and posterior legs of the cranial base on the mid-sagittal plane. The anterior leg is measured from $\mathrm{Na}$ to Ts-point. The posterior leg is measured from Ts-point to the projected midpoint between the right and left G-points on the mid-sagittal plane; G(mid). $\mathrm{G}$ (mid) was determined by taking the average $\mathrm{z}$ (horizontal) and $\mathrm{y}$ (vertical) coordinates for $\mathrm{Gr}$ and $\mathrm{Gl}$ with their $\mathrm{x}$ (transverse) coordinates being zero. To calculate the cranial flexure angle a constructed triangle on the mid-sagittal plane had to be generated. (See figure 12) This was accomplished with the directly measured and known length from $\mathrm{Na}$ to Ts. The other two unknown legs of this constructed triangle were determined using coordinate data for the landmarks $\mathrm{Na}$, Ts and $\mathrm{G}(\mathrm{mid})$ and the Pythagorean Theorem. Once the midline triangle was constructed the internal angle at Ts (Cranial flexure) was determined using the Law of Cosine. Diagrammatic representations of the cranial base and the cranial flexure calculation are shown in Figures 12 through 14. 
Figure 12. Cranial base polygon

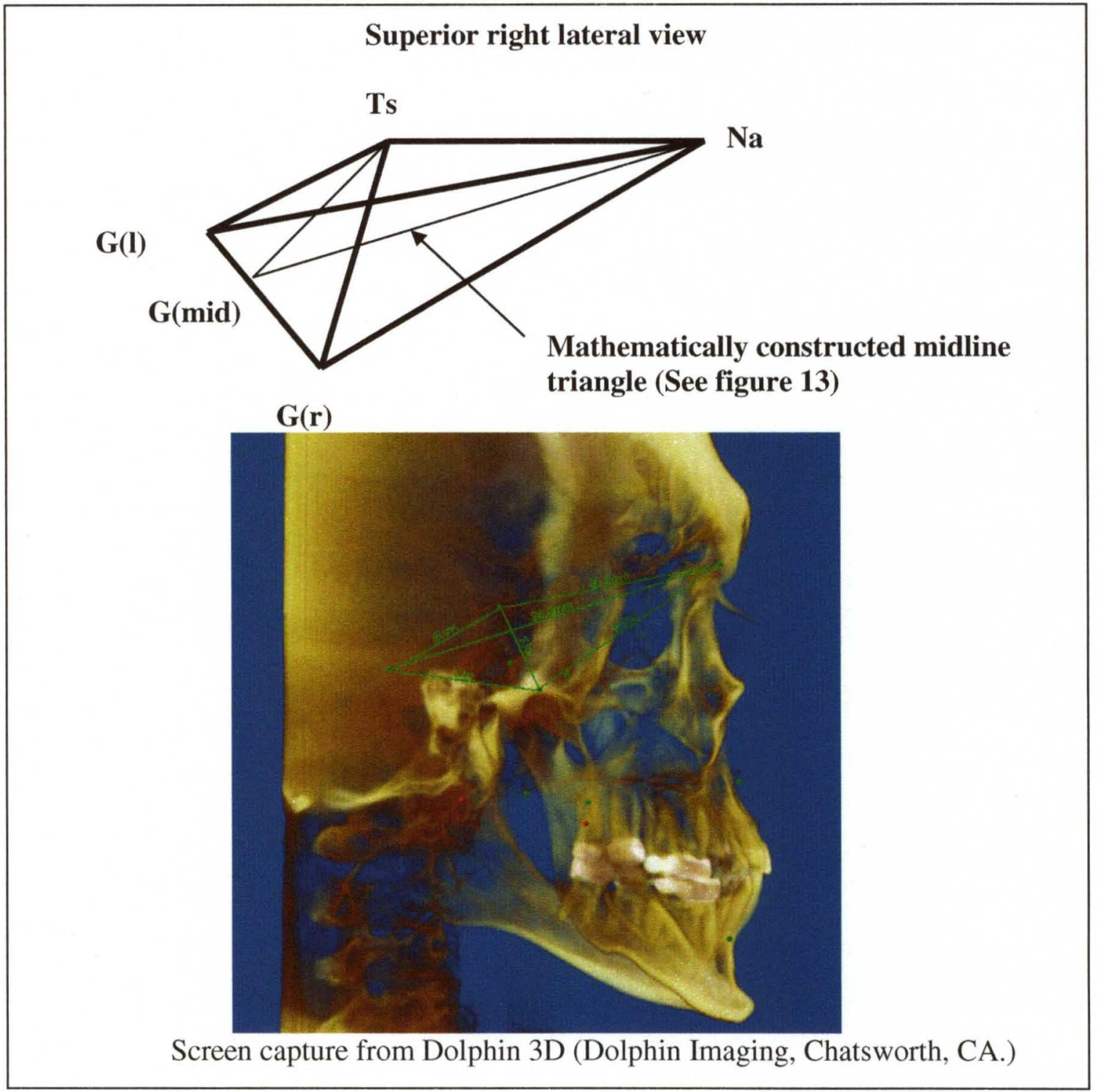

Figure 13. Cranial base midline triangle

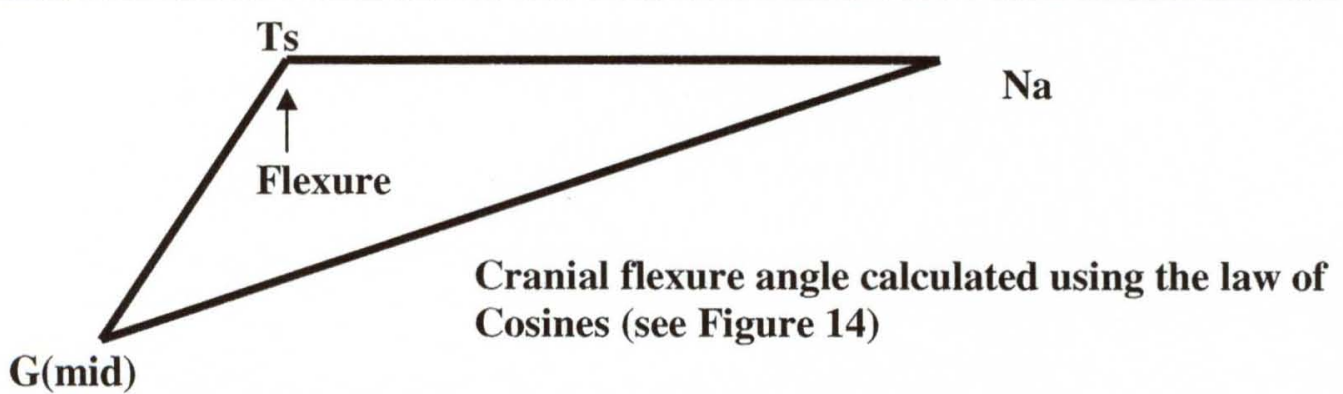


Figure 14. Mathematical calculation

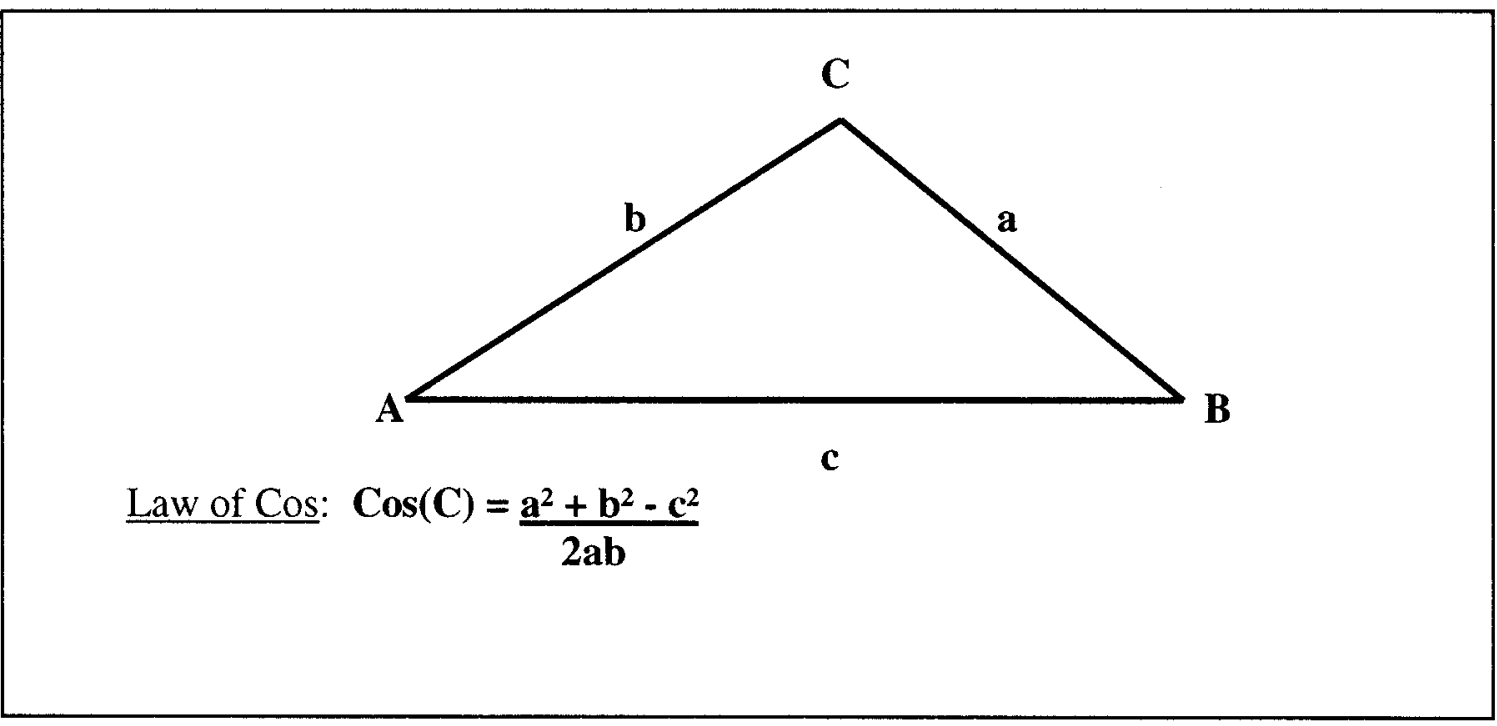

The next cranial base variable measured was cranial deflection. This measurement defines the flatness or uprightness of the entire cranial base regardless of its flexure. Conventionally cranial deflection has been defined as the angle formed between the Frankfort horizontal line (FH) and the Na-Basion / Articulare line. Since this 3D study establishes the posterior cranial base limit as the Glenoid Fossa, we define cranial deflection as the angle formed between $\mathrm{FH}$ and the $\mathrm{Na}-\mathrm{G}(\mathrm{mid})$ line on the mid-sagittal plane. A right triangle was constructed with the $\mathrm{z}$ (horizontal) dimension of $\mathrm{G}(\mathrm{mid})$ along the SCBP line and the $y$ (vertical) dimensions perpendicular to the SCBP line on the mid-sagittal plane. The hypotenuse of the triangle is the Na to $G($ mid) line. The cranial deflection angle was then calculated using simple trigonometry. (See Figures 15 and 16.) 
Figure 15. Cranial deflection

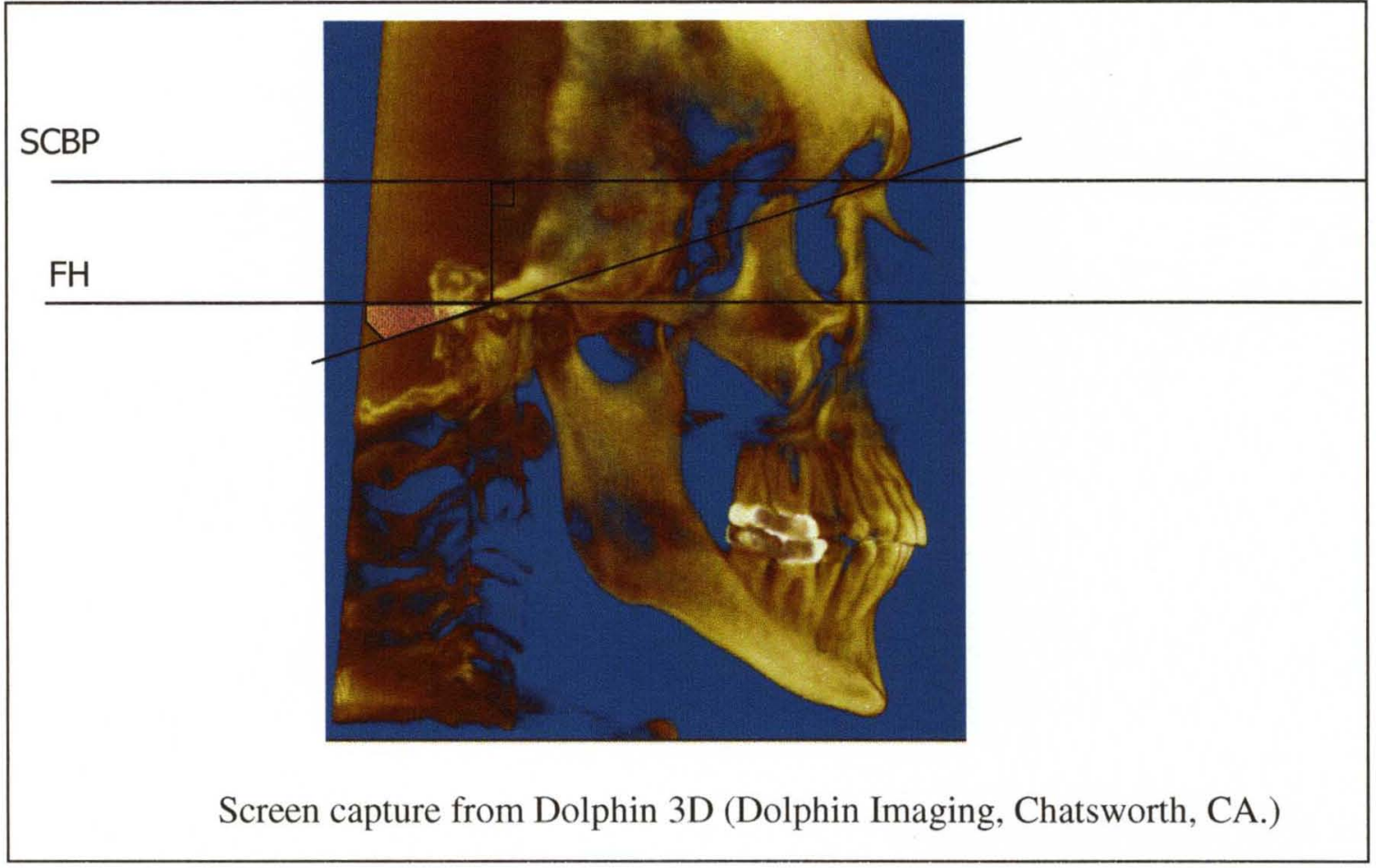

Figure 16. Cranial Deflection calculation

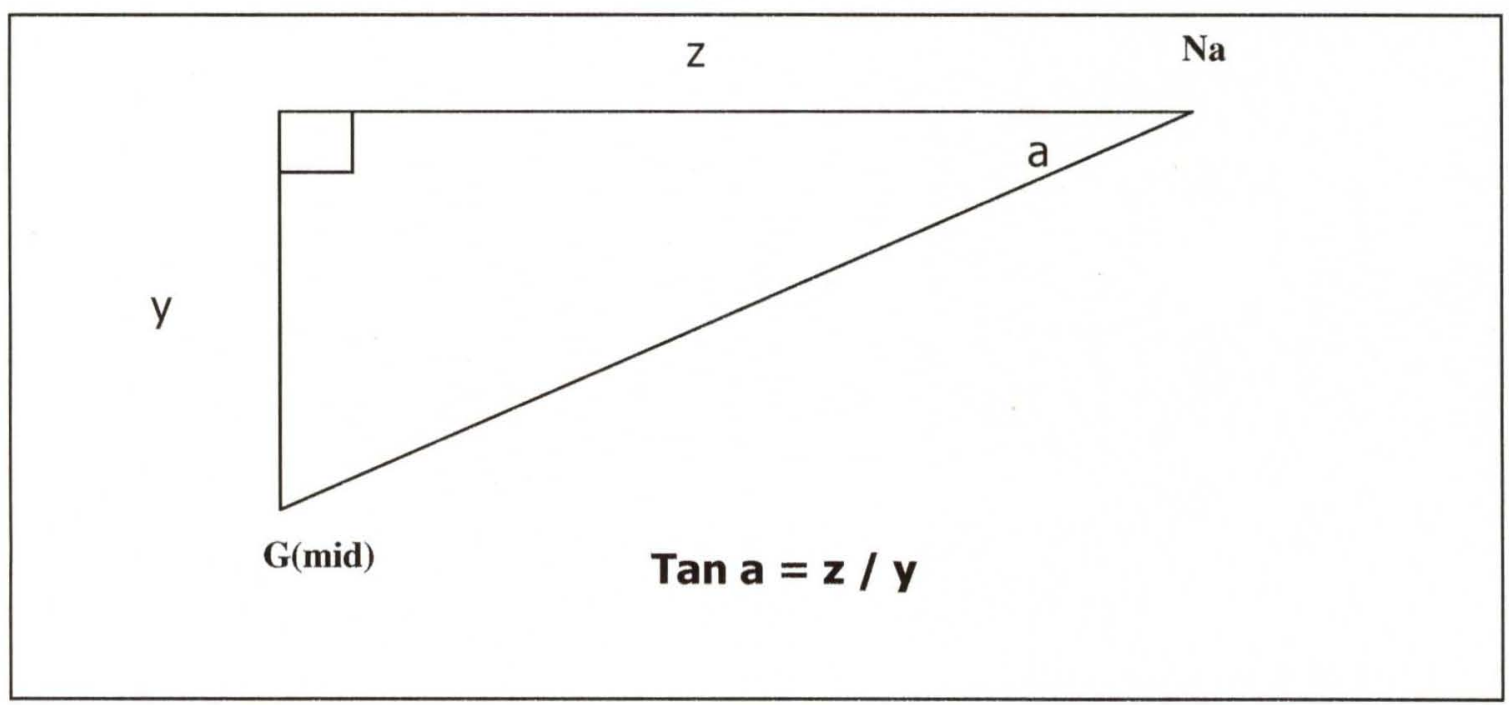

The angle (a) in figure 16 was calculated with the average $\mathrm{z}$ and $\mathrm{y}$ dimensions for $\mathrm{G}(\mathrm{mid})$. The calculated angle (a) corresponds to the cranial deflection angle formed between $\mathrm{FH}$ and the $\mathrm{Na}-\mathrm{G}(\mathrm{mid})$ line which is the shaded angle shown in figure 15. 
It is hypothesized that cranial flexure and deflection are co-dependent and that one cannot be analyzed without the other. Knowing the flexure angle is meaningless without knowing the overall orientation of the cranial base in space using cranial deflection. Let us look at each of these two variables in isolation. Enlow's hypothesis was that as cranial flexure opens to a more obtuse angle there is a corresponding increase in jaw discrepancy toward class II. Conversely as the flexure decreased to a more acute angle the corresponding jaw discrepancy would move toward class III. Now let us examine cranial deflection independently. Enlow also hypothesized that as the cranial base becomes more flat, i.e. the deflection angle becomes more acute there would be a corresponding increase in jaw discrepancy toward class II. Conversely as the deflection becomes more obtuse representing the cranial base becoming more upright the jaw discrepancy would move toward class III. These hypotheses make intuitive sense when taken in isolation. The reality is that these variables are inter-related and can compensate for one another. An individual who has a very obtuse cranial flexure angle that would otherwise contribute to more of a Class II jaw relationship may have a very upright cranial deflection angle bringing the cranial base back toward Class I. It was therefore important in this study to analyze the flexure and deflection variables together.

\section{Intra-observer Reliability}

The final step in this study is a procedure to test the investigator's accuracy in landmark identification. This step accomplishes two goals. The first goal is to show the reproducibility of the new landmarks. Second, it attempts to eliminate landmark placement as a potential error in the study analysis. Ten subjects from the original forty 
subjects traced were selected at random for repeat tracing. The coordinate data was again exported to a spread sheet. $\mathrm{X}, \mathrm{Y}$, and $\mathrm{Z}$ coordinates for each landmark were recorded as $\mathrm{x} 1, \mathrm{y} 1$, and $\mathrm{z} 1$ for the original tracing and $\mathrm{x} 2, \mathrm{y} 2$, and $\mathrm{z} 2$ for the repeat tracing. An interclass correlation analysis was then completed to see the accuracy of each landmark placement in all three dimensions. 


\section{RESULTS}

The raw data for landmark coordinates, ANB angle measurement, and Na-Ts linear distance for all 40 subjects is provided in Appendix A. The results of calculated measurements for $\mathrm{ANB}, \mathrm{AB}$ angle, $\mathrm{LP}$ angle, cranial flexure, and cranial deflection are listed in Table 5 (in descending ANB value order) along with descriptive statistics; mean and standard deviation data.

Three linear regression analyses were performed using cranial flexure and deflection as the joint explanatory variables and the three jaw position angles as separate response variables. A $95 \%$ confidence interval was included. The results of the initial regression analyses are shown in Table 6. The interaction term for cranial flexure and deflection combined was not significant for any of the response variables and was therefore dropped. Each of the multiple linear regressions resulted in low R squared values and high p-values. The only explanatory variable that resulted in a p-value below the 0.05 level was cranial deflection matched with ANB. A second regression analysis was therefore performed matching cranial deflection to ANB independent of cranial flexure. The result of this regression analysis is shown in Table 7.

The raw $x, y$, and $z$ coordinate data for the original and repeat tracings used for the landmark accuracy test are listed in Table 9 in Appendix B. Table 8 shows the results of the interclass correlation analysis performed on the first and second tracing data. 
Table 5. Mean values for Horizontal Jaw discrepancy and Cranial Base descriptive parameters for each Subject.

\begin{tabular}{|c|c|c|c|c|c|}
\hline \multirow[b]{2}{*}{ Subject } & \multicolumn{3}{|c|}{$\begin{array}{c}\text { Horizontal Jaw discrepancy } \\
\text { Parameters }\end{array}$} & \multicolumn{2}{|c|}{ Cranial Base Parameters } \\
\hline & $\begin{array}{l}\text { LP angle } \\
\text { (degrees) }\end{array}$ & $\begin{array}{c}A N B \\
\text { (degrees) }\end{array}$ & $\begin{array}{l}\text { AB angle } \\
\text { (degrees) }\end{array}$ & $\begin{array}{c}\text { Cranial } \\
\text { flexure } \\
\text { (degrees) }\end{array}$ & $\begin{array}{c}\text { Cranial } \\
\text { Deflection } \\
\text { (degrees) }\end{array}$ \\
\hline 39 & 15.0164 & 9.7000 & 5.4403 & 149.6230 & 24.4934 \\
\hline 34 & 15.1893 & 9.5000 & 9.8768 & 143.4711 & 19.1923 \\
\hline 28 & 12.0694 & 7.7000 & 7.0173 & 147.4466 & 19.9605 \\
\hline 32 & 12.5956 & 7.2000 & 5.9217 & 131.9020 & 22.5316 \\
\hline 9 & 11.1669 & 6.8000 & 3.2068 & 139.0325 & 25.7020 \\
\hline 4 & 12.9913 & 6.2000 & 2.8136 & 132.8927 & 21.6242 \\
\hline 14 & 15.0785 & 6.1000 & 5.8019 & 138.0319 & 21.3301 \\
\hline 6 & 14.6947 & 6.0000 & 5.0234 & 138.5330 & 17.9616 \\
\hline 3 & 12.1306 & 5.7000 & 4.3794 & 123.6329 & 20.0931 \\
\hline 40 & 12.5843 & 5.7000 & 7.8676 & 120.2558 & 18.3292 \\
\hline 21 & 15.8230 & 5.6000 & 3.8414 & 137.2000 & 20.0067 \\
\hline 35 & 13.7515 & 5.1000 & 4.2425 & 136.5664 & 21.7953 \\
\hline 17 & 15.9454 & 4.8000 & 5.9967 & 147.9623 & 17.3953 \\
\hline 15 & 11.7564 & 4.7000 & 2.1673 & 140.9161 & 19.6489 \\
\hline 37 & 9.6139 & 4.5000 & 1.4524 & 129.8050 & 20.1786 \\
\hline 25 & 12.7535 & 4.1000 & 3.2774 & 129.0466 & 18.4803 \\
\hline 29 & 15.6909 & 4.1000 & 4.4564 & 141.8280 & 18.1044 \\
\hline 26 & 10.0022 & 4.0000 & 3.5111 & 120.4005 & 17.5274 \\
\hline 11 & 13.1092 & 3.8000 & 1.8882 & 122.8333 & 20.4944 \\
\hline Mean & 11.96 & 3.24 & 2.32 & 134.26 & 19.71 \\
\hline$S D$ & 2.37 & 3.25 & 3.21 & 8.68 & 2.30 \\
\hline
\end{tabular}


Table 5. Mean values for Horizontal Jaw discrepancy and Cranial Base descriptive parameters for each Subject. (continued)

\begin{tabular}{|c|c|c|c|c|c|}
\hline \multirow[b]{2}{*}{ Subject } & \multicolumn{3}{|c|}{$\begin{array}{c}\text { Horizontal Jaw discrepancy } \\
\text { Parameters }\end{array}$} & \multicolumn{2}{|c|}{ Cranial Base Parameters } \\
\hline & $\begin{array}{l}\text { LP angle } \\
\text { (degrees) }\end{array}$ & $\begin{array}{c}A N B \\
\text { (degrees) }\end{array}$ & $\begin{array}{l}\text { AB angle } \\
\text { (degrees) }\end{array}$ & $\begin{array}{l}\text { Cranial flexure } \\
\text { (degrees) }\end{array}$ & $\begin{array}{c}\text { Cranial } \\
\text { Deflection } \\
\text { (degrees) }\end{array}$ \\
\hline 20 & 10.3551 & 3.0000 & 1.8600 & 141.3143 & 19.8333 \\
\hline 24 & 12.0814 & 2.9000 & 2.9174 & 129.8830 & 21.8218 \\
\hline 10 & 10.3946 & 2.8000 & 2.7984 & 126.1714 & 16.5281 \\
\hline 13 & 12.2836 & 2.8000 & 2.2739 & 131.3846 & 24.2469 \\
\hline 2 & 14.0731 & 2.6000 & 2.1364 & 124.6531 & 15.9709 \\
\hline 5 & 10.4836 & 2.6000 & 2.6603 & 123.6407 & 22.4703 \\
\hline 1 & 14.3324 & 1.8000 & -1.0230 & 135.3446 & 18.8178 \\
\hline 18 & 11.7903 & 1.8000 & -0.2748 & 134.2631 & 19.4575 \\
\hline 27 & 14.3018 & 1.8000 & -1.3334 & 136.8722 & 19.9675 \\
\hline 12 & 9.2567 & 1.1000 & 0.8660 & 129.9491 & 14.1416 \\
\hline 31 & 8.0616 & 1.1000 & 1.7075 & 141.2399 & 20.4328 \\
\hline 22 & 10.8264 & 0.9000 & 1.2261 & 119.5278 & 19.2696 \\
\hline 7 & 10.1995 & 0.3000 & -0.3367 & 147.5914 & 19.7611 \\
\hline 33 & 8.2192 & -0.9000 & -2.0793 & 126.5548 & 18.8965 \\
\hline 36 & 8.4361 & -1.5000 & -1.6297 & 150.7761 & 18.9451 \\
\hline 38 & 11.1263 & -1.7000 & -1.8939 & 125.4163 & 19.8178 \\
\hline 16 & 7.0994 & -2.9000 & -5.4592 & 130.2324 & 17.0205 \\
\hline 23 & 9.8639 & -3.2000 & -3.4459 & 144.1461 & 21.3989 \\
\hline 19 & 9.3557 & -4.1000 & -2.8720 & 139.3153 & 18.0218 \\
\hline Mean & 11.96 & 3.24 & 2.32 & 134.26 & 19.71 \\
\hline$S D$ & 2.37 & 3.25 & 3.21 & 8.68 & 2.30 \\
\hline
\end{tabular}


Table 6. Multiple linear regression analysis results

\begin{tabular}{|c|c|c|c|c|c|}
\hline & & Response & variable: & NB angle & \\
\hline & & $95 \%$ con & dence in & & \\
\hline Variable & Estimate & Lower & Upper & t- value & p-value \\
\hline Cranial flexure & 0.0167 & -0.1034 & 0.1367 & 0.2811 & 0.7802 \\
\hline Cranial deflection & 0.4583 & 0.0059 & 0.9107 & 2.0527 & 0.0472 \\
\hline F- statistic & 2.371 & & & & \\
\hline R squared & 0.1136 & & & & \\
\hline Adjusted $\mathrm{R}$ squared & 0.06571 & & & & \\
\hline Overall p-value & 0.1074 & & & & \\
\hline & & Response & variable: & $B$ angle & \\
\hline & & $95 \%$ con & dence in & vals & \\
\hline Variable & Estimate & Lower & Upper & $t$ value & p-value \\
\hline Cranial flexure & 0.0108 & -0.1136 & 0.1353 & 0.1762 & 0.8611 \\
\hline Cranial deflection & 0.213 & -0.256 & 0.6821 & 0.9202 & 0.3634 \\
\hline F- statistic & 0.4946 & & & & \\
\hline R squared & 0.02604 & & & & \\
\hline Adjusted $\mathrm{R}$ squared & -0.02661 & & & & \\
\hline Overall p-value & 0.6138 & & & & \\
\hline & & Response & variable: & $P$ angle & \\
\hline & & $95 \%$ con & dence in & vals & \\
\hline Variable & Estimate & Lower & Upper & $t$ value & $\mathrm{p}$-value \\
\hline Cranial flexure & 0.0447 & -0.0459 & 0.1354 & 0.9994 & 0.3241 \\
\hline Cranial deflection & 0.123 & -0.2187 & 0.4647 & 0.7292 & 0.4705 \\
\hline F- statistic & 0.9602 & & & & \\
\hline $\mathrm{R}$ squared & 0.04934 & & & & \\
\hline Adjusted R squared & -0.002045 & & & & \\
\hline Overall p-value & 0.3921 & & & & \\
\hline
\end{tabular}

Table 7. Linear regression analysis results for ANB / Cranial deflection

\begin{tabular}{lccccc}
\hline \multicolumn{5}{c}{ Response variable: ANB angle } \\
\hline Variable & Estimate & Lower & Upper & t value & p-value \\
Cranial deflection & 0.4715 & 0.0349 & 0.908 & 2.1863 & $\mathbf{0 . 0 3 5}$ \\
\hline Correlation & & & & & \\
coefficient & $\mathbf{0 . 3 3 4}$ & & & &
\end{tabular}


Table 8. Landmark accuracy test results Matrix

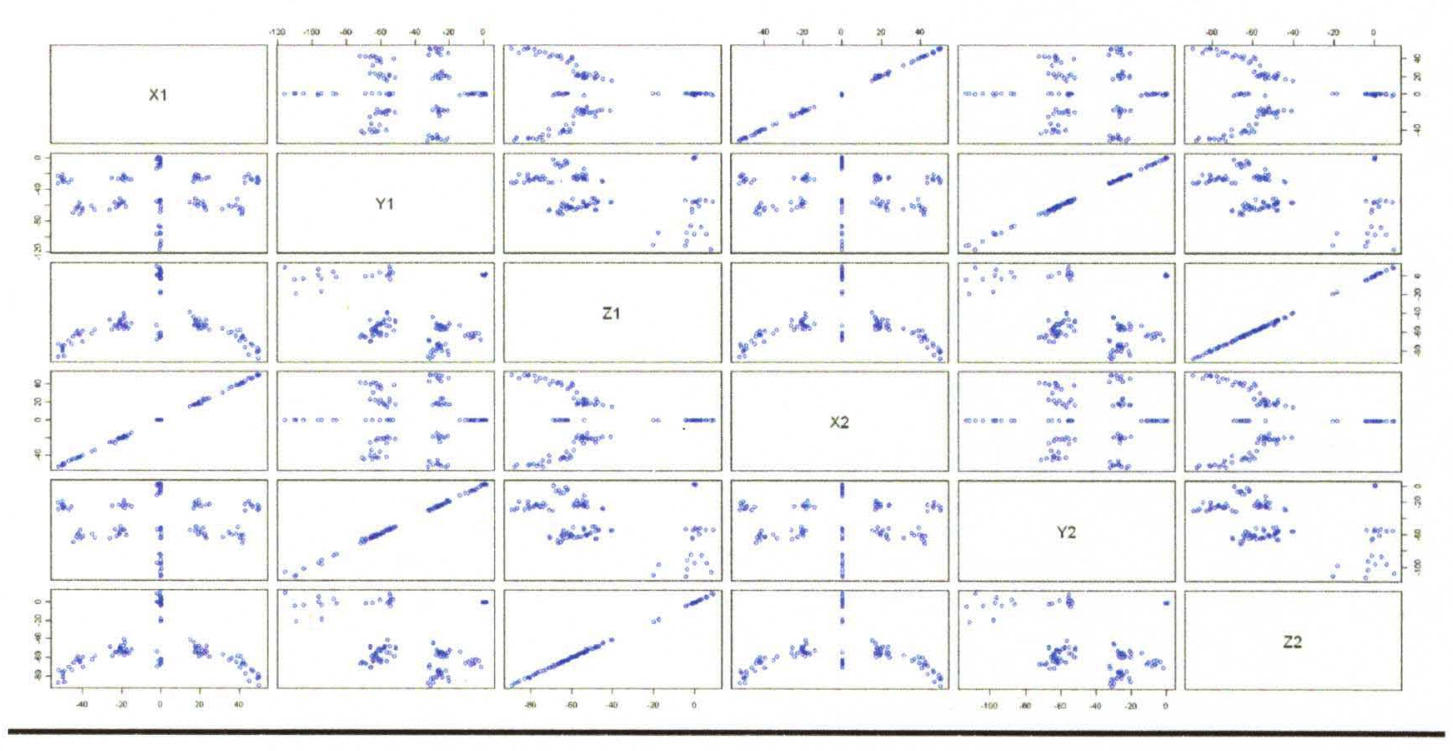

\begin{tabular}{|c|c|}
\hline Dimension & $\begin{array}{c}\text { Interclass } \\
\text { correlation }\end{array}$ \\
\hline \hline $\mathrm{X}$ & 1 \\
\hline $\mathrm{Y}$ & 0.999 \\
\hline $\mathrm{Z}$ & 1 \\
\hline
\end{tabular}




\section{DISCUSSION}

The initial multiple regression tests analyzing the correlation between the combined cranial base variables with the three respective response variables indicated low $\mathrm{R}^{2}$ values and non significant inferences $(\mathrm{p}>0.05)$. These results indicate that there are no significant correlations between the combined cranial base variables and the jaw discrepancy variables for the selected sample. The results of the statistical analysis also identify no significant correlation between the jaw discrepancy variables and each of the respective cranial base variables independent of each other. The only significant correlation was for cranial deflection matched with ANB. However, the resulting Pearson correlation coefficient value of 0.334 indicates a weak correlation at best. Furthermore, the original hypothesis was that as the cranial deflection angle increased, the cranial base would become more upright, resulting in more of a class III jaw discrepancy; i.e. decreasing ANB. If the hypothesized effect of cranial deflection on ANB would have been observed, then the Pearson correlation coefficient should have resulted in a negative value. This negative value would have indicated an inverse relationship. The observed positive 0.334 value that we observed therefore indicates not only a weak correlation but the opposite of the hypothesized result as well. The overall analyses conducted resulted in either non-significant or weak correlations. These results make validating any of the proposed hypotheses impossible.. 
While the observed results do not match the originally proposed hypotheses, some promising results were obtained for the landmark identification test. Table 8 shows the results of this test. As stated above, $25 \%$ of the subjects were randomly selected for a repeat tracing of all landmarks and measurements. Each of the landmarks in the first tracing was tested against the landmark data in the second run. The interclass correlation results with values of nearly 1.0 for all dimensions showed that the landmarks were placed with a high degree of consistency. While the differences in some of the dimensions of the landmarks varied, the mean difference between the first and second tracings was approximately $0.5 \mathrm{~mm}$ for all dimensions. The anatomy of the mandible for example made it difficult to consistently identify the $\mathrm{Y}$ (vertical) dimension of B point. However, the overall mean error of $0.5 \mathrm{~mm}$ falls within the size of the Dolphin 3D's landmark dot. This means that landmark identification error most likely did not significantly contribute to the overall error of this study. It also indicates that landmark identification in the $2 \mathrm{D}$ slice environment of the $3 \mathrm{D}$ software can be accurate enough for study.

Why the results of the study do not validate the hypotheses is unknown. Inherent in the design of this study there are multiple areas that may have contributed error and impacted the observed results. With the limitation of time on the study it was therefore necessary to conduct this research retrospectively using existing images. This method increases the error inherent in the system. There was no way to control for several factors that could have impacted the results. First, all of the images were of adult individuals. Many of whom were many decades past adolescence. While we could observe whether an individual had received orthognathic surgery or significant facial 
trauma there was no way to ascertain whether a subject had received orthodontic treatment in their youth. Headgear treatment, functional appliance therapy of any sort, or even orthodontic elastic therapy could influence the $\mathrm{A} / \mathrm{P}$ position of the jaws and therefore affect the results of this study. A prospective study design would be more appropriate where subjects are selected for inclusion early in adulthood with prior orthodontic treatment as exclusion criteria. The second factor of this retrospective design is that the total sample size ended up being quite low. This was due to the fact that the database of images at the University Of Louisville School Of Dentistry included a limited number of scans that met the inclusion criteria of this study. With this sample size there would have been no way to make any definitive conclusions even if the results of this study matched more closely to the hypotheses presented. Again, a prospective design with specific selection criteria would not necessarily be limited by time and therefore could continue indefinitely until a sample size was obtained that fulfilled an initial power analysis. This would ensure that any results obtained, positive or negative, would lead to more solid conclusions.

Another possibility that may have led to low correlation values is that the method of analyzing the anatomy used in this study may have been erroneous. While the mathematics of calculating the selected variables is not in doubt, the selection of some of the landmarks leading to the calculated variables may be debatable. Whether the glenoid fossa should be used as the posterior limit of the cranial base remains in question for example. The same can be said for whether Nasion should be used as the anterior most limit of the cranial base. However, the results of this study do not necessarily negate the validity of the selected landmarks. As stated above, further research with better controls 
should be conducted to make more definitive statements about the usefulness of such landmarks.

In an effort to reduce another source of error an attempt was made to eliminate the effect of jaw size on the A/P discrepancy of the jaws. This was accomplished by including the LP angle which attempted to relate the most posterior aspects of the traced jaw structures. The authors of this study admit that while the goal of eliminating jaw size from this research question was an important one, we cannot confirm that this new method of relating the jaws at their posterior limits accomplished the goal. The potential variability in the landmark placed on the lingual of the mandible may have significantly affected the resulting LP angle. Also, the LP angle did not account for any vertical growth problems between the maxilla and the mandible. For example, a vertical growth pattern in the maxilla that would rotate the mandible down and back would have resulted in a higher LP angle with the cranial base potentially having no contributing effect.

The final possibility why the results of this study did not match the hypotheses presented is that there may actually be no significant correlation between the anatomy of the cranial base and $\mathrm{A} / \mathrm{P}$ jaw discrepancy. Also, there may be an anatomical link between the cranial base morphology and the position of the jaws but the complicated multifactorial nature of their relationship may be too difficult to establish definitively. For example, two individuals may share the exact same cranial flexure angle and yet have totally different classes of skeletal malocclusion due to the compensatory effects of the cranial deflection angle, jaw size, and vertical growth of the jaws. It may therefore be impossible to ever determine any cephalometric norms for cranial base measurements in isolation. The possibility that there is not an identifiable "if A then B" relationship 
between the cranial base and jaw positions may be true. But this study can neither confirm that there is a correlation between the cranial base morphology and skeletal malocclusion nor definitively state that there isn't one. 


\section{CONCLUSIONS}

The original research question proposed was whether there were anatomical landmarks visible in the 3D image that would provide a better ability than in two dimensions to analyze the cranial base morphology and its relation to skeletal malocclusion. The original hypothesis proposed was there would be a positive correlation between cranial flexure angle and an inverse correlation between cranial deflection angle and the $\mathrm{A} / \mathrm{P}$ jaw discrepancy variable angles. It was also hypothesized that the two cranial base variables together would correlate more significantly with $\mathrm{A} / \mathrm{P}$ jaw discrepancy than either variable taken in isolation. The results of this study cannot confirm any of the hypotheses originally proposed. A positive result observed was that consistent landmark identification and measurement in the $2 \mathrm{D}$ slice environment of Dolphin 3D was simple to accomplish with a little practice. Future research conducted on 3D images should use this technique to minimize error in landmark placement. Whether there is or is not a relationship between cranial base morphology and skeletal malocclusion remains to be seen. Future study on this subject using 3D technology should be aimed at reducing the potential error presented in this study to more definitively answer the research question. 


\section{REFERENCES}

1. Anderson D, Popovich F. Relation of cranial base flexure to cranial form and mandibular position. Am J Phys Anthropol. 1983 Jun;61(2):181-7.

2. Anderson D, Popovich F. Correlations among craniofacial angles and dimensions in Class I and Class II malocclusions. Angle Orthod: 1989 Spring;59(1):37-42.

3. Andria, L. Correlation of the cranial base angle and its components with other dentalskeletal variables and treatment time. Angle Orthod: Vol. 74, No. 3, pp. 361-366.

4. Ballrick, J. Image distortion and spatial resolution of a commercially available conebeam computed tomography machine. Am J Orthod Dentofacial Orthop 2008;134:57382.

5. Brown, A. Linear Accuracy of Cone Beam CT Derived 3D Images. Angle Orthod: Vol. 79, No. 1, pp. 150-157.

6. Cattaneo P.M. Comparison between conventional and cone-beam computed tomography-generated cephalograms. Am J Orthod Dentofacial Orthop 2008;134:798802.

7. Cavalcanti, M. Craniofacial measurements based on 3D-CT volume rendering: implications for clinical applications. Dentomaxillofacial Radiology (2004) 33, 170-176.

8. Cho, H. A Three-Dimensional Cephalometric Analysis. J Clin Orthod. 2009 Apr;43(4):235-52.

9. Dhopatkar, A. An investigation into the relationship between cranial base angle and malocclusion. Angle Orthod: Vol. 72, No. 5, pp. 456-463.

10. Dibbets J. M. H. Morphological associations between the Angle classes. European Journal of Orthodontics 18 (1996) 111-118.

11. Grauer, D. Working with DICOM craniofacial images. Am J Orthod Dentofacial Orthop 2009;136:460-70.

12. Hassan, B. Accuracy of three-dimensional measurements obtained from cone beam computed tomography surface-rendered images for cephalometric analysis: influence of patient scanning position. European Journal of Orthodontics 31 (2009) 129-134. 
13. Hopkin, G.B. The cranial base as an etiological factor in malocclusion. AngleOrthod: Vol. 38, No 3, pp. 250-255.

14. Kerr WJ, Adams CP. Cranial base and jaw relationship. Am J Phys Anthropol. 1988 Oct;77(2):213-20.

15. KumarV. Comparison of conventional and cone beam CT synthesized cephalograms. Dentomaxillofacial Radiology (2007) 36, 263-269.

16. Lascala, C. Analysis of the accuracy of linear measurements obtained by cone beam computed tomography (CBCT-NewTom). Dentomaxillofacial Radiology (2004) 33, 291-294.

17. Muramatsu, A. Reproducibility of Maxillofacial Anatomic Landmarks on 3Dimensional Computed Tomographic Images Determined with the 95\% Confidence Ellipse Method. Angle Orthod: Vol. 78, No. 3, pp. 396-402.

18. Mori, Y. An accurate 3D cephalometric system: a solution for correction of cephalic malpositioning. Journal of Orthodontics. Vol. 28: 2001. 143-149.

19. Moshiri, M. Accuracy of linear measurements from imaging plate and lateral cephalometric images derived from cone-beam computed tomography. Am J Orthod Dentofacial Orthop 2007;132:550-60.

20. Oliveira, A. Observer reliability of three-dimensional cephalometric landmark identification on cone-beam computerized tomography. Oral Surg Oral Med Oral Pathol Oral Radiol Endod 2009;107:256-265.

21. Olszewski, R. 3D CT-based cephalometric analysis: 3D cephalometric theoretical concept and software. Neuroradiology (2006) 48:853-862.

22. Olszewski, R. Three-dimensional computed tomography cephalometric craniofacial analysis: experimental validation in vitro. Int. J. Oral Maxillofac. Surg. 2007; 36: 828833.

23. Olszewski, R. Accuracy of three-dimensional (3D) craniofacial cephalometric landmarks on a low-dose 3D computed tomography. Dentomaxillofacial Radiology (2008) 37, 261-267.

24. Periago, D. Linear Accuracy and Reliability of Cone Beam CT Derived 3Dimensional Images Constructed Using an Orthodontic Volumetric Rendering Program. The Angle Orthodontist: Vol. 78, No. 3, pp. 387-395.

25. Pinsky, H. Accuracy of three-dimensional measurements using cone-beam CT. Dentomaxillofacial Radiology (2006) 35, 410-416. 
26. Polat, $O$. Changes in cranial base morphology in different malocclusions. Orthod Craniofacial Res 10, 2007; 216-221.

27. Proff, P. Cranial base feature in skeletal class III patients. Angle Orthod: Vol. 78, No. 3, pp. 433-439.

28. Quintero, J. Craniofacial imaging in orthodontics: Historical perspective, current status, and future developments. Angle Orthod: Vol. 69, No. 6, pp. 491-506.

29. Stratemann, S. Comparison of cone beam computed tomography imaging with physical measures. Dentomaxillofacial Radiology (2008) 37, 80-93.

30. Vandana Kumara In Vivo Comparison of Conventional and Cone Beam CT Synthesized Cephalograms. Angle Orthod: Vol 78, No 5, 2008.

31. Yushkevich, P. User-guided 3D active contour segmentation of anatomical structures: Significantly improved efficiency and reliability. NeuroImage 31 (2006) 1116 $-1128$. 


\section{APPENDIX A}

\section{Original landmark tracing data}

\begin{tabular}{|c|c|c|c|}
\hline & Transverse & Vertical & AP \\
\hline Pnt 1- & $-x--$ & $--Y-$ & $-2--$ \\
\hline Landmark - 1 Nasion & -1.4 & 0.2 & -0.1 \\
\hline Landmark - 2 A point & 0 & -52.5 & 4.1 \\
\hline Landmark - 3 B point & 1.1 & -89.6 & 5.7 \\
\hline Landmark - 4 TS point & -1.6 & -6.1 & -59.8 \\
\hline Landmark - 5 Right 6 point & -47.1 & -26.7 & -74.9 \\
\hline Landmark - 6 Left G point & 42.5 & -25.2 & -77.4 \\
\hline Landmark - 7 Left L point & 36.1 & -58.9 & -61.9 \\
\hline Landmark - 8 Right 1 point & -40.2 & -59.3 & -59.3 \\
\hline Landmark - 9 Right $P$ point & -24.2 & -55.8 & -44.7 \\
\hline Landmark - 10 Left P point & 20.7 & -55.8 & -46.3 \\
\hline 2-Pt Distance $\mathrm{mm}$ - (N to Ts) & & & 60.1 \\
\hline 3-Pt Angle $\cong-1$ (ANB) & & & 1.8 \\
\hline Pnt 2- & $-x-$ & $-Y--$ & $-z-$ \\
\hline Landmark - 1 Nasion & -0.1 & 0.3 & 0.4 \\
\hline Landmark - 2 A point & 0.2 & -46.9 & 2 \\
\hline Landmark - 3 B point & -0.1 & -83.1 & -1.1 \\
\hline Landmark - 4 TS point & -0.2 & -3.7 & -62.4 \\
\hline Landmark - 5 Right 6 point & -44.2 & -20.8 & -74.3 \\
\hline Landmark - 6 Left $G$ point & 47 & -21.7 & -74.2 \\
\hline Landmark - 7 Left L point & 37.8 & -55.2 & -57.9 \\
\hline Landmark - 8 Right L point & -33.9 & -54.5 & -58.9 \\
\hline Landmark - 9 Right P point & -17.8 & -50.3 & -44.4 \\
\hline Landmark - 10 Left P point & 18.5 & -50.3 & -44.9 \\
\hline 2-Pt Distance $\mathrm{mm}$ - ( $\mathrm{N}$ to $\mathrm{Ts})$ & & & 63.2 \\
\hline 3-Pt Angle :-1 & & & 2.6 \\
\hline Pnt 3- & $-x-$ & $-Y-$ & $-2 \cdots$ \\
\hline Landmark - 1 Nasion & -0.3 & -0.1 & 0.1 \\
\hline Landmark - 2 A point & -2.4 & -64.3 & 5.1 \\
\hline Landmark - 3 B point & -1.5 & -113.6 & -3.6 \\
\hline Landmark - 4 TS point & -0.3 & -4.8 & -70.8 \\
\hline Landmark - 5 Right 6 point & -47.1 & -30.7 & -86.4 \\
\hline Landmark - 6 Left $G$ point & 46.2 & -32 & -85 \\
\hline Landmark - 7 Left L point & 38.7 & -71.2 & -73.1 \\
\hline Landmark - 8 Right $L$ point & -41.6 & -70.7 & -71.8 \\
\hline Landmark - 9 Right $P$ point & -24.3 & -66.1 & -57.8 \\
\hline Landmark - 10 Left $P$ point & 21.5 & -66.7 & -56.6 \\
\hline 2-Pt Distance $\mathrm{mm}$ - (N to Ts) & & & 70.8 \\
\hline 3-Pt Angle $9-1$ & & & 5.7 \\
\hline Pnt 4- & $-x-$ & $-Y_{--}$ & $-z-$ \\
\hline Landmark - 1 Nasion & 0.5 & -0.4 & -0.2 \\
\hline Landmark - 2 A point & -0.6 & -54.1 & 8.2 \\
\hline Landmark - 3 B point & -0.6 & -93.6 & 3.6 \\
\hline Landmark - 4 TS point & 0.5 & -9.8 & -57.5 \\
\hline Landmark - 5 Right G point & -46.9 & -26.1 & -69.1 \\
\hline Landmark - 6 Left $G$ point & 46.9 & -29.2 & -70.4 \\
\hline Landmark - 7 Left L point & 35.5 & -62.7 & -56.5 \\
\hline Landmark - 8 Right L point & -35.7 & -61.7 & 56.6 \\
\hline Landmark - 9 Right P point & -23.5 & -56.9 & -42.1 \\
\hline Landmark - 10 Left P point & 20.1 & -58.1 & -42.3 \\
\hline 2-Pt Distance $\mathrm{mm}$ - (N to Ts) & & & 58.6 \\
\hline 3-Pt Angle $\Omega-1$ & & & 6.2 \\
\hline
\end{tabular}

\begin{tabular}{|c|c|c|c|}
\hline & Transverse & Vertical & AP \\
\hline Pnt 21- & $--x--$ & $-Y_{--}$ & $-z-$ \\
\hline Landmark - 1 Nasion & 0 & 0.4 & -0.5 \\
\hline Landmark - 2 A point & 0 & -57.7 & 4.6 \\
\hline Landmark - 3 B point & 0 & -83.4 & -1 \\
\hline Landmark - 4 TS point & 0 & -9.6 & -63.3 \\
\hline Landmark - 5 Right $G$ point & -44.9 & -27.6 & -77.4 \\
\hline Landmark - 6 Left G point & 43.6 & -29.2 & -78.6 \\
\hline Landmark - 7 Left L point & 34.7 & -59.8 & -61.9 \\
\hline Landmark - 8 Right L point & -36 & -57.7 & -60.2 \\
\hline Landmark - 9 Right $P$ point & -20.5 & -54.3 & -44.3 \\
\hline Landmark - 10 Left $P$ point & 20.1 & -54.3 & -44.5 \\
\hline 2-Pt Distance $\mathrm{mm}$ - ( $\mathrm{N}$ to $\mathrm{Ts}$ ) & & & 63.9 \\
\hline 3-Pt Angle $9-1$ & & & 5.6 \\
\hline Pnt 22- & $-x-$ & $-Y--$ & $-z--$ \\
\hline Landmark - 1 Nasion & 0 & 0.7 & 0.1 \\
\hline Landmark - 2 A point & 0 & -52 & -1.1 \\
\hline Landmark - 3 B point & 0 & -84.1 & -2.9 \\
\hline Landmark - 4 TS point & 0 & -4.1 & -58.9 \\
\hline Landmark - 5 Right $G$ point & -46.1 & -24.5 & -69.7 \\
\hline Landmark - 6 Left G point & 47.7 & -23.5 & -67.6 \\
\hline Landmark - 7 Left L point & 36.4 & -59.8 & -55.7 \\
\hline Landmark - 8 Right L point & -38.3 & -58.9 & -55.3 \\
\hline Landmark - 9 Right P point & -22.2 & -52.9 & -44.3 \\
\hline Landmark - 10 Left P point & 21.5 & -52.9 & -44 \\
\hline 2-Pt Distance $\mathrm{mm}$ - ( $\mathrm{N}$ to $\mathrm{Ts}$ ) & & & 59.2 \\
\hline 3-Pt Angle $:-1$ & & & 0.9 \\
\hline Pnt 23- & $-x-$ & $-Y_{-\infty}$ & $-z-$ \\
\hline Landmark - 1 Nasion & -1.1 & 0 & 0 \\
\hline Landmark - 2 A point & 0.5 & -51.4 & 0.3 \\
\hline Landmark - 3 B point & 0 & -93 & 5.9 \\
\hline Landmark - 4 TS point & 0 & -12.3 & -60.5 \\
\hline Landmark - 5 Right $G$ point & -45.8 & -29.9 & -77.7 \\
\hline Landmark -6 Left $G$ point & 49.3 & -29.9 & -74.9 \\
\hline Landmark - 7 Left L point & 37 & -62.6 & -55.1 \\
\hline Landmark - 8 Right L point & -38 & -62.2 & -58 \\
\hline Landmark - 9 Right P point & -19.2 & -55.8 & -46.4 \\
\hline Landmark - 10 Left $P$ point & 18 & -56.4 & -45 \\
\hline 2-Pt Distance $\mathrm{mm}$ - ( $\mathrm{N}$ to $\mathrm{Ts}$ ) & & & 61.6 \\
\hline 3-Pt Angle $9-1$ & & & -3.2 \\
\hline Pnt 24- & $--x-$ & $--Y--$ & $-\mathrm{z-}-$ \\
\hline Landmark - 1 Nasion & -1.1 & 0.1 & 0.4 \\
\hline Landmark - 2 A point & 0 & -55.2 & 0.2 \\
\hline Landmark - 3 B point & 0 & -88.3 & -4.3 \\
\hline Landmark - 4 TS point & 0 & -8.1 & -59.3 \\
\hline Landmark - 5 Right G point & -41.7 & -28.7 & -72.8 \\
\hline Landmark - 6 Left G point & 43.7 & -29.6 & -72.8 \\
\hline Landmark - 7 Left L point & 34.5 & -58.7 & -55.3 \\
\hline Landmark - 8 Right L point & -35.3 & -58.1 & -56.3 \\
\hline Landmark - 9 Right P point & -18.7 & -54.8 & -43.4 \\
\hline Landmark - 10 Left P point & 18.1 & -54.8 & -43.2 \\
\hline 2-Pt Distance $\mathrm{mm}$ - ( $\mathrm{N}$ to Ts) & & & 60 \\
\hline 3-Pt Angle $:-1$ & & & 2.9 \\
\hline
\end{tabular}




\section{Appendix A (cont.)}

\begin{tabular}{|c|c|c|c|}
\hline Pnt 5- & $-x-$ & $-Y--$ & $-2-$ \\
\hline Landmark - 1 Nasion & -0.1 & 0.7 & 3.1 \\
\hline Landmark - 2 A point & -0.3 & -56.7 & 3.9 \\
\hline Landmark - 3 B point & -1.8 & -99 & -0.7 \\
\hline Landmark - 4 TS point & 0.6 & -9.4 & -59.2 \\
\hline Landmark - 5 Right $G$ point & -45.1 & -28.4 & -72.6 \\
\hline Landmark - 6 Left $G$ point & 42.3 & -32.4 & -74.4 \\
\hline Landmark - 7 Left L point & 33.7 & -65.4 & -58.2 \\
\hline Landmark - 8 Right L point & -38.1 & -64.3 & -56.8 \\
\hline Landmark - 9 Right $P$ point & -19.8 & -58.9 & -45.1 \\
\hline Landmark - 10 Left $P$ point & 17.6 & -60.9 & -45.9 \\
\hline 2-Pt Distance $\mathrm{mm}$ - (N to Ts) & & & 62.6 \\
\hline 3-Pt Angle $9-1$ & & & 2.6 \\
\hline Pnt 6- & $-x-$ & $-Y--$ & $-z-$ \\
\hline Landmark - 1 Nasion & 0.8 & -0.1 & -0.2 \\
\hline Landmark - 2 A point & -1.7 & -60.3 & 3.1 \\
\hline Landmark - 3 B point & -0.6 & -96.7 & -5.4 \\
\hline Landmark - 4 TS point & 1.4 & -6.9 & -64.6 \\
\hline Landmark - 5 Right G point & -49.7 & -28.4 & -84.3 \\
\hline Landmark - 6 Left G point & 48.5 & -25.9 & -83.2 \\
\hline Landmark - 7 Left L point & 40.9 & -66.5 & -66.9 \\
\hline Landmark - 8 Right L point & -42.1 & -66.2 & -67.8 \\
\hline Landmark - 9 Right P point & -21.4 & -58.9 & -50.6 \\
\hline Landmark - 10 Left P point & 19.2 & -58.9 & -49.3 \\
\hline 2-Pt Distance $\mathrm{mm}-(\mathrm{N}$ to $\mathrm{Ts})$ & & & 65.2 \\
\hline 3-Pt Angle $=-1$ & & & 6 \\
\hline Pnt 7 - & $-x-$ & $-\mathrm{Y}$ & $-2 \cdots$ \\
\hline Landmark - 1 Nasion & 0.2 & -0.9 & -0.4 \\
\hline Landmark - 2 A point & -1.1 & -59.2 & 0.5 \\
\hline Landmark - 3 B point & -1.6 & -102.1 & 1.1 \\
\hline Landmark - 4 TS point & 0.1 & -9.6 & -67.2 \\
\hline Landmark - 5 Right G point & -46.8 & -31.7 & -91.3 \\
\hline Landmark - 6 Left G point & 44.8 & -33.9 & -91.3 \\
\hline Landmark - 7 Left L point & 41.3 & -74.2 & -64.7 \\
\hline Landmark -8 Right L point & -41.4 & .74 .2 & -64.8 \\
\hline Landmark - 9 Right P point & -21.6 & -61.5 & -51.6 \\
\hline Landmark - 10 Left P point & 23.4 & -61.5 & -51.2 \\
\hline 2-Pt Distance $\mathrm{mm}$ - ( $\mathrm{N}$ to $\mathrm{Ts}$ ) & & & 67.1 \\
\hline 3-Pt Angle $9-1$ & & & 0.3 \\
\hline Pnt 8- & $-x-$ & $-Y--$ & $--z--$ \\
\hline Landmark - 1 Nasion & -1.1 & 1.3 & 0.8 \\
\hline Landmark-2 A point & 0.3 & -60.9 & 2.3 \\
\hline Landmark - 3 B point & 0.3 & -105.3 & -3.8 \\
\hline Landmark - 4 TS point & -0.1 & -5.9 & -66.1 \\
\hline Landmark - 5 Right G point & -50.6 & -25 & -76.6 \\
\hline Landmark - 6 Left G point & 49.6 & -24.7 & -81.1 \\
\hline Landmark - 7 Left L point & 42.1 & -64.6 & -64.9 \\
\hline Landmark - 8 Right L point & -43.3 & -65.1 & -62.2 \\
\hline Landmark - 9 Right P point & -21 & -60.3 & -51.7 \\
\hline Landmark - 10 Left $P$ point & 22.6 & -60.3 & .52 .7 \\
\hline 2-Pt Distance $\mathrm{mm}$ - (N to Is) & & & 66.3 \\
\hline 3-Pt Angle $:-1$ & & & 3.5 \\
\hline Pnt 9- & $-x-$ & $-Y-$ & $-z--$ \\
\hline Landmark - 1 Nasion & 0.8 & -0.4 & -0.2 \\
\hline Landmark - 2 A point & 0.2 & -64 & 8 \\
\hline Landmark - 3 B point & -0.3 & -117.8 & 1.4 \\
\hline Landmark - 4 TS point & -0.3 & -18.1 & -65 \\
\hline Landmark - 5 Right G point & -52.7 & -36.7 & -74.9 \\
\hline Landmark - 6 Left G point & 51.5 & -36.7 & -77.6 \\
\hline Landmark - 7 Left L point & 41.5 & .74 & -59.5 \\
\hline Landmark - 8 Right $L$ point & -45.1 & -72.4 & -58.9 \\
\hline Landmark - 9 Right $P$ point & -24.2 & -72.3 & -44.4 \\
\hline Landmark - 10 Left P point & 22.2 & -70.9 & -45.1 \\
\hline 2-Pt Distance $\mathrm{mm}$ - ( $\mathrm{N}$ to $\mathrm{Ts}$ ) & & & 67 \\
\hline 3-Pt Angle $:-1$ & & & 6.8 \\
\hline
\end{tabular}

\begin{tabular}{|l|r|r|r|}
\hline Pnt 25- & $-X-$ & \multicolumn{1}{|c|}{$-Y-$} & \multicolumn{1}{|c|}{$-\mathrm{Z}-$} \\
\hline Landmark - 1 Nasion & -0.6 & 0.4 & 0.6 \\
\hline Landmark - 2 A point & -0.3 & -59.2 & 1.9 \\
\hline Landmark - 3 B point & 0 & -94.3 & -3.5 \\
\hline Landmark - 4 TS point & 0 & -3.4 & -59.3 \\
\hline Landmark - 5 Right G point & -43 & -25.7 & -74.6 \\
\hline Landmark - 6 Left G point & 42.6 & -24.9 & -76.8 \\
\hline Landmark - 7 Left L point & 33.3 & -63.2 & -61.6 \\
\hline Landmark - 8 Right L point & -34.1 & -63.6 & -62.7 \\
\hline Landmark - 9 Right P point & -19.8 & -60.1 & -47.8 \\
\hline Landmark - 10 Left P point & 19.3 & -58.9 & -47.8 \\
\hline 2-Pt Distance mm - (N to Ts) & & & 59.7 \\
\hline 3-Pt Angle $\mathrm{O}-1$ & & & 4.1 \\
\hline
\end{tabular}

\begin{tabular}{|l|r|r|r|}
\hline Pnt 26-S & \multicolumn{1}{|l|}{$-X-$} & \multicolumn{1}{|c|}{$-\gamma--$} & $-Z--$ \\
\hline Landmark - 1 Nasion & -0.8 & -1.2 & -0.2 \\
\hline Landmark - 2 A point & 0.6 & -57.2 & -2.1 \\
\hline Landmark - 3 B point & 3.4 & -92.9 & -7.8 \\
\hline Landmark - 4 TS point & -0.8 & -1.8 & -63.5 \\
\hline Landmark - 5 Right G point & -51.3 & -24.1 & -75.2 \\
\hline Landmark - 6 Left G point & 48.1 & -23.4 & -75.2 \\
\hline Landmark - 7 Left L point & 38.2 & -55.3 & -61.9 \\
\hline Landmark - 8 Right L point & -39.2 & -58.1 & -60 \\
\hline Landmark - 9 Right P point & -22.6 & -51.3 & -50.2 \\
\hline Landmark - 10 Left P point & 19.7 & -51.3 & -51.7 \\
\hline 2-Pt Distance mm - (N to TS) & & & 63.3 \\
\hline 3-Pt Angle O - 1 & & & 4 \\
\hline
\end{tabular}

\begin{tabular}{|c|c|c|c|}
\hline Pnt 27- & $-x--$ & $-Y-$ & $-z--$ \\
\hline Landmark - 1 Nasion & -0.6 & 0.4 & -0.3 \\
\hline Landmark - 2 A point & -0.6 & -54.5 & 5.5 \\
\hline Landmark - 3 B point & -0.6 & -116 & 8.2 \\
\hline Landmark - 4 TS point & -0.6 & -8 & -67.7 \\
\hline Landmark - 5 Right $G$ point & -52.3 & -32.7 & -87.8 \\
\hline Landmark - 6 Left $G$ point & 50.1 & -31.5 & -88.9 \\
\hline Landmark -7 Left L point & 41.5 & -72 & -66.6 \\
\hline Landmark - 8 Right L point & -44.6 & -70 & -65.5 \\
\hline Landmark - 9 Right P point & -26 & -66.3 & -48.1 \\
\hline Landmark - 10 Left P point & 23.2 & -66.3 & -47.8 \\
\hline 2-Pt Distance $m m$ - ( $N$ to $T s$ ) & & & 68.3 \\
\hline 3-Pt Angle $9-1$ & & & 1.8 \\
\hline
\end{tabular}

\begin{tabular}{|c|c|c|c|}
\hline Pnt 28- & $-x-$ & $--Y-$ & $-z-$ \\
\hline Landmark - 1 Nasion & -0.7 & -0.6 & 0.2 \\
\hline Landmark - 2 A point & -0.7 & -61.4 & 1.6 \\
\hline Landmark - 3 B point & -0.7 & -111.3 & -12.1 \\
\hline Landmark - 4 TS point & -0.7 & -14.1 & -64.9 \\
\hline Landmark - 5 Right G point & -54.6 & -31 & -81.5 \\
\hline Landmark - 6 Left G point & 47.3 & -28.2 & -81.5 \\
\hline Landmark - 7 Left $L$ point & 36.2 & -68.9 & -67.9 \\
\hline Landmark - 8 Right L point & -43.7 & -70 & -65.9 \\
\hline Landmark - 9 Right $P$ point & -25.1 & -63.2 & -51.1 \\
\hline Landmark - 10 Left $P$ point & 18.4 & -63.2 & -53 \\
\hline 2-Pt Distance $\mathrm{mm}-(\mathrm{N}$ to Ts) & & & 66.7 \\
\hline 3-Pt Angle $:-1$ & & & 7.7 \\
\hline
\end{tabular}

\begin{tabular}{|c|c|c|c|}
\hline Pnt 29- & $-\mathrm{x}-$ & $-\gamma-\cdot$ & $-z--$ \\
\hline Landmark - 1 Nasion & 0.1 & -0.2 & 0.1 \\
\hline Landmark - 2 A point & 0 & -61 & -1 \\
\hline Landmark - 3 B point & 2.4 & -98.8 & -8.7 \\
\hline Landmark - 4 TS point & -1.3 & -8.4 & -64.7 \\
\hline Landmark - 5 Right $G$ point & .51 .4 & .28 .8 & -83.3 \\
\hline Landmark - 6 Left G point & 48.7 & -25.7 & -83.4 \\
\hline Landmark - 7 Left L point & 40.8 & -65.5 & .69 .6 \\
\hline Landmark - 8 Right L point & -38 & -65.5 & -68.9 \\
\hline Landmark - 9 Right $P$ point & -20.1 & -59 & -50.1 \\
\hline Landmark - 10 Left P point & 20.8 & -59 & -51.6 \\
\hline 2-Pt Distance $\mathrm{mm}$ - ( $\mathrm{N}$ to Ts) & & & 65.3 \\
\hline 3-Pt Angle : - 1 & & & 4.1 \\
\hline
\end{tabular}




\section{Appendix A (cont.)}

\begin{tabular}{|c|c|c|c|}
\hline Pnt 10- & $-x-$ & $-Y-$ & $-z--$ \\
\hline Landmark - 1 Nasion & -0.2 & 0.7 & -0.1 \\
\hline Landmark - 2 A point & 0 & -55.5 & 0 \\
\hline Landmark - 3 B point & 0 & -98.2 & -4.8 \\
\hline Landmark - 4 TS point & -1.2 & -6.9 & -65.2 \\
\hline Landmark - 5 Right $G$ point & -48.3 & -21.9 & -73.8 \\
\hline Landmark - 6 Left G point & 46.6 & -21.9 & -73.8 \\
\hline Landmark - 7 Left L point & 35.6 & -56.7 & -59.4 \\
\hline Landmark - 8 Right L point & -38 & -55.6 & -59.8 \\
\hline Landmark - 9 Right $P$ point & -20 & -54.2 & -49.4 \\
\hline Landmark - 10 Left $P$ point & 18.6 & -54.8 & -49.2 \\
\hline 2-Pt Distance $\mathrm{mm}$ - ( $\mathrm{N}$ to Ts) & & & 65.5 \\
\hline 3-Pt Angle : - 1 & & & 2.8 \\
\hline Pnt 11- & $-\mathrm{x}-$ & $-Y--$ & $-z-$ \\
\hline Landmark - 1 Nasion & -0.2 & 0.4 & 0.3 \\
\hline Landmark - 2 A point & -2.8 & -52.5 & .3 .1 \\
\hline Landmark - 3 B point & 0 & -91 & 0.1 \\
\hline Landmark - 4 TS point & -0.1 & -7 & -60.8 \\
\hline Landmark - 5 Right $\mathrm{G}$ point & -49.1 & -26.2 & -71.9 \\
\hline Landmark - 6 Left G point & 45.7 & -27.1 & -70.7 \\
\hline Landmark - 7 Left L point & 39.4 & .59 .6 & -58 \\
\hline Landmark - 8 Right L point & -39.9 & -57.2 & -60.9 \\
\hline Landmark - 9 Right $P$ point & -19.6 & -56.5 & -46.6 \\
\hline Landmark - 10 Left $P$ point & 18.5 & -56.5 & -45.1 \\
\hline 2-Pt Distance $\mathrm{mm}$ - (N to Ts) & & & 61.7 \\
\hline 3-Pt Angle $\varrho-1$ & & & 3.8 \\
\hline Pnt 12- & $-x-$ & $-Y-$ & $-2-$ \\
\hline Landmark - 1 Nasion & -1.4 & -0.6 & -0.2 \\
\hline Landmark - 2 A point & -0.3 & -56.5 & -0.6 \\
\hline Landmark - 3 8 point & -0.7 & -86 & -1.9 \\
\hline Landmark - 4 TS point & -1.8 & -1.8 & -68.6 \\
\hline Landmark - 5 Right 6 point & -50.3 & -21.2 & -81 \\
\hline Landmark - 6 Left G point & 45.2 & -20.7 & -85.3 \\
\hline Landmark - 7 Left L point & 38.7 & -60.3 & -64.6 \\
\hline Landmark - 8 Right L point & -41.9 & -61.8 & -63.4 \\
\hline Landmark - 9 Right P point & -23.5 & -56.7 & -53.9 \\
\hline Landmark - 10 Left P point & 21.6 & -55.3 & -54.2 \\
\hline 2-Pt Distance $\mathrm{mm}-(\mathrm{N}$ to $\mathrm{Ts})$ & & & 68.3 \\
\hline 3-Pt Angle $:-1$ & & & 1.1 \\
\hline Pnt 13- & $--x-$ & $-Y--$ & $--z--$ \\
\hline Landmark - 1 Nasion & 0.3 & 0.7 & 0.2 \\
\hline Landmark - 2 A point & 0 & -60.6 & 1.7 \\
\hline Landmark - 3 B point & 0 & -95.7 & -2.1 \\
\hline Landmark - 4 TS point & -1.8 & -11.5 & -61.2 \\
\hline Landmark - 5 Right $\mathrm{G}$ point & -50.6 & -32.5 & -72.1 \\
\hline Landmark - 6 Left G point & 46.3 & -34.7 & -77.1 \\
\hline Landmark - 7 Left L point & 36.9 & -69.1 & -62.4 \\
\hline Landmark - 8 Right L point & -41.1 & $-69,6$ & -58.9 \\
\hline Landmark - 9 Right 9 point & -20.3 & -62.8 & -44.7 \\
\hline Landmark - 10 Left P point & 18.1 & -62.8 & -46.4 \\
\hline 2-Pt Distance $\mathrm{mm}$ - (N to Ts) & & & 62.4 \\
\hline 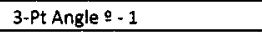 & & & 2.8 \\
\hline Pnt 14- & $-x-$ & $-Y-$ & $-z--$ \\
\hline Landmark - 1 Nasion & 0 & 0.3 & 0.6 \\
\hline Landmark - 2 A point & 0 & -63.3 & 1.3 \\
\hline Landmark - 3 B point & 0 & -99.4 & -8.8 \\
\hline Landmark - 4 TS point & 0 & -12.2 & -61.7 \\
\hline Landmark - 5 Right G point & -46.5 & -28.5 & -73.5 \\
\hline Landmark - 6 Left G point & 48.7 & -29.8 & -75.8 \\
\hline Landmark - 7 Left L point & 35.3 & -60.7 & -62.7 \\
\hline Landmark - 8 Right $L$ point & -34.8 & -62.9 & -63.1 \\
\hline Landmark - 9 Right $P$ point & -17.6 & -56.9 & -46 \\
\hline Landmark - 10 Left P point & 17.3 & -56.9 & -46.5 \\
\hline 2-Pt Distance $\mathrm{mm}$ - (N to Ts) & & & 63 \\
\hline 3-Pt Angle $\varrho-1$ & & & 6.1 \\
\hline
\end{tabular}

\begin{tabular}{|c|c|c|c|}
\hline Pnt 30- & $-x-$ & $-Y-$ & $-2--$ \\
\hline Landmark - 1 Nasion & 0 & 0.1 & 0 \\
\hline Landmark - 2 A point & 0 & -54.9 & 1.5 \\
\hline Landmark - 3 B point & 0 & -94.6 & -3.5 \\
\hline Landmark - 4 TS point & 0 & -7.2 & -62.2 \\
\hline Landmark - 5 Right $\mathrm{G}$ point & -45.6 & -27.4 & .73 .9 \\
\hline Landmark - 6 Left G point & 43.3 & -24.8 & -76.9 \\
\hline Landmark - 7 Left L point & 34.8 & -59.8 & -61.8 \\
\hline Landmark - 8 Right L point & -35.1 & -60.7 & -62.3 \\
\hline Landmark - 9 Right $P$ point & -19.3 & -55.1 & -46.9 \\
\hline Landmark - 10 Left P point & 19.5 & -55.1 & -47.1 \\
\hline 2-Pt Distance $\mathrm{mm}$ - ( $\mathrm{N}$ to Ts) & & & 62.6 \\
\hline 3-Pt Angle $\subseteq-1$ & & & 3.6 \\
\hline Pnt 31- & $-x-$ & $-Y-$ & $-2--$ \\
\hline Landmark - 1 Nasion & 0 & 0.1 & -0.2 \\
\hline Landmark - 2 A point & 0 & -69 & -1.1 \\
\hline Landmark - 3 B point & 0 & -110.7 & $-4,4$ \\
\hline Landmark - 4 TS point & 0 & -11.2 & -65.3 \\
\hline Landmark - 5 Right 6 point & -50.1 & -29.8 & -80.4 \\
\hline Landmark - 6 Left $G$ point & 49.3 & -31 & -82.8 \\
\hline Landmark - 7 Left L point & 41.9 & -69.1 & -66.9 \\
\hline Landmark - 8 Right L point & -41.4 & -71.4 & -64.4 \\
\hline Landmark - 9 Right $P$ point & -22.5 & -62.8 & -55 \\
\hline Landmark - 10 Left $P$ point & 22.4 & -63.5 & -56.4 \\
\hline 2-Pt Distance $\mathrm{mm}-(\mathrm{N}$ to $\mathrm{Ts}$ ) & & & 66 \\
\hline 3-Pt Angle $\cong-1$ & & & 1.1 \\
\hline
\end{tabular}

\begin{tabular}{|l|r|r|r|}
\hline Pnt 32- & \multicolumn{1}{|c|}{$-X-Y-$} & \multicolumn{1}{|c|}{$-Z$} \\
\hline Landmark - 1 Nasion & 0 & 0.5 & -0.2 \\
\hline Landmark - 2 A point & 0 & -62.8 & 3.5 \\
\hline Landmark - 3 B point & 0 & -112.8 & -8.2 \\
\hline Landmark - 4 TS point & 0 & -10.1 & -65.8 \\
\hline Landmark - 5 Right G point & -54.3 & -34 & -78.6 \\
\hline Landmark - 6 Left G point & 51.1 & -33 & -82.9 \\
\hline Landmark - 7 Left L point & 41.8 & -62.6 & -64.9 \\
\hline Landmark - 8 Right L point & -41.7 & -64.5 & -62.5 \\
\hline Landmark - 9 Right P point & -23.9 & -62.2 & -48.8 \\
\hline Landmark - 10 Left P point & 21.7 & -63.1 & -50.2 \\
\hline 2-Pt Distance mm - (N to Ts) & & & 66.4 \\
\hline 3-Pt Angle 9 - 1 & & & 7.2 \\
\hline
\end{tabular}

\begin{tabular}{|l|r|r|r|}
\hline Pnt 33- & \multicolumn{1}{|c|}{$-X--$} & $-Y-$ & \multicolumn{1}{|c|}{$-Z$} \\
\hline Landmark - 1 Nasion & 0 & -0.9 & 0 \\
\hline Landmark - 2 A point & 0 & -53 & 2.5 \\
\hline Landmark - 3 B point & 0 & -96.4 & 6 \\
\hline Landrnark - 4 TS point & 0 & -6.5 & -66.1 \\
\hline Landmark - 5 Right G point & -50.2 & -27.3 & -78.4 \\
\hline Landmark - 6 Left G point & 49.5 & -26.1 & -77.6 \\
\hline Landmark - 7 Left L point & 40.8 & -63.1 & -59.6 \\
\hline Landmark - 8 Right L point & -42.3 & -62.9 & -60.2 \\
\hline Landmark -9 Right P point & -21.2 & -58.7 & -50.9 \\
\hline Landmark - 10 Left P point & 20.7 & -58.7 & -50.7 \\
\hline 2-Pt Distance mm - (N to Ts) & & & 66.3 \\
\hline 3-Pt Angle 0 - 1 & & & -0.9 \\
\hline
\end{tabular}

\begin{tabular}{|c|c|c|c|}
\hline Pnt 34 & $-x-$ & $-Y--$ & $-z-$ \\
\hline Landmark - 1 Nasion & 0 & 0.6 & -0.1 \\
\hline Landmark - 2 A point & 0 & -65 & -1 \\
\hline Landmark - 3 B point & 0 & -109.7 & -20.1 \\
\hline Landmark - 4 TS point & -1.2 & -9.5 & -63.7 \\
\hline Landmark - 5 Right $G$ point & -49.5 & -30 & -86.4 \\
\hline Landmark - 6 Left G point & 50.5 & -28.2 & -80.8 \\
\hline Landmark - 7 Left L point & 40.5 & -66.2 & -70.4 \\
\hline Landmark - 8 Right $L$ point & -39.7 & -66.4 & -71 \\
\hline Landmark -9 Right $P$ point & -17.7 & -61.9 & -52.4 \\
\hline Landmark - 10 Left $P$ point & 18.9 & -61.3 & -53 \\
\hline 2-Pt Distance $\mathrm{mm}$ - ( $\mathrm{N}$ to $\mathrm{Ts}$ ) & & & 64.5 \\
\hline 3-Pt Angle $:-1$ & & & 9.5 \\
\hline
\end{tabular}




\section{Appendix A (cont.)}

\begin{tabular}{|c|c|c|c|}
\hline Pnt 15- & $-x-$ & $-Y--$ & $-z--$ \\
\hline Landmark - 1 Nasion & 0 & 0.1 & 0 \\
\hline Landmark - 2 A point & 0 & -50.7 & 4.9 \\
\hline Landmark - 3 8 point & 0 & -87.2 & 1.6 \\
\hline Landmark - 4 TS point & 0 & -10.6 & -59.3 \\
\hline Landmark - 5 Right $G$ point & -44.6 & -26 & -73.8 \\
\hline Landmark - 6 Left G point & 46.2 & -26.2 & -72.4 \\
\hline Landmark - 7 Left L point & 37 & -57.9 & -57.6 \\
\hline Landmark -8 Right $L$ point & -35.1 & -57.9 & -57 \\
\hline Landmark - 9 Right $P$ point & -16 & -52.6 & -45.1 \\
\hline Landmark - 10 Left P point & 19 & -52.6 & -45.4 \\
\hline 2-Pt Distance $\mathrm{mm}$ - ( $\mathrm{N}$ to $\mathrm{Ts})$ & & & 60.4 \\
\hline 3-Pt Angle $9-1$ & & & 4.7 \\
\hline Pnt 16- & $-x-$ & $-y--$ & $-z--$ \\
\hline Landmark - 1 Nasion & 0 & 0.9 & -0.2 \\
\hline Landmark - 2 A point & 0 & -52.6 & 6.4 \\
\hline Landmark - 3 B point & 0 & -85.8 & 14.6 \\
\hline Landmark - 4 TS point & -1.3 & -6.3 & -64.8 \\
\hline Landmark - 5 Right G point & -47.2 & -23.8 & -78.5 \\
\hline Landmark -6 Left $G$ point & 52.5 & -22.7 & -73.4 \\
\hline Landmark - 7 Left L point & 41.5 & -55 & -50.3 \\
\hline Landmark - 8 Right L point & -41 & -55 & -54.7 \\
\hline Landmark - 9 Right P point & -19.1 & -53.8 & -46.8 \\
\hline Landmark - 10 Left P point & 20.4 & -53.8 & -44.5 \\
\hline 2-Pt Distance $\mathrm{mm}$ - ( $\mathrm{N}$ to Ts) & & & 64.8 \\
\hline 3-Pt Angle $9-1$ & & & -2.9 \\
\hline Pnt 17- & $-x-$ & $-Y--$ & $-\mathrm{Z--}$ \\
\hline Landmark - 1 Nasion & 0 & 0.3 & 0.1 \\
\hline Landmark - 2 A point & 0 & -51.8 & -2 \\
\hline Landmark - 3 B point & $\underline{0}$ & -97.1 & -12.2 \\
\hline Landmark - 4 TS point & 0 & -7.8 & -59.3 \\
\hline Landmark - 5 Right G point & -43.5 & -24.4 & -79 \\
\hline Landmark - 6 Left $G$ point & 43.4 & -25.1 & -79 \\
\hline Landmark - 7 Left L point & 34.9 & -55.9 & -64.7 \\
\hline Landmark - 8 Right $L$ point & -35.9 & -54 & -61.1 \\
\hline Landmark - 9 Right P point & -19.5 & -50.2 & -46.9 \\
\hline Landmark - 10 Left $P$ point & 19.5 & -51.6 & -47.5 \\
\hline 2-Pt Distance $\mathrm{mm}$ - ( $\mathrm{N}$ to Ts) & & & 59.6 \\
\hline 3-Pt Angle 0.1 & & & 4.8 \\
\hline Pnt 18- & $-x-$ & $-Y--$ & $--Z--$ \\
\hline Landmark - 1 Nasion & 0 & 0.9 & -0.2 \\
\hline Landmark - 2 A point & 0 & .52 .2 & 5.2 \\
\hline Landmark - 3 B point & 0 & -83.4 & 5.6 \\
\hline Landmark - 4 TS point & -0.5 & -5.8 & -54.5 \\
\hline Landmark - 5 Right G point & -47.2 & -23.4 & -67.3 \\
\hline Landmark - 6 Left G point & 45.9 & -25 & -69.7 \\
\hline Landmark - 7 Left $L$ point & 36.8 & -56.5 & -52.3 \\
\hline Landmark - 8 Right L point & -37.6 & -58 & -51.4 \\
\hline Landmark - 9 Right P point & -18.4 & -52.4 & -39.9 \\
\hline Landmark - 10 Left $P$ point & 19.2 & -52.4 & -39.9 \\
\hline 2-Pt Distance $\mathrm{mm}$ - (N to Ts) & & & 54.6 \\
\hline 3-Pt Angle $9-1$ & & & 1.8 \\
\hline Pnt 19- & $-x-$ & $-\gamma-$ & $-z-$ \\
\hline Landmark - 1 Nasion & 0.2 & 0.1 & 0.1 \\
\hline Landmark - 2 A point & 0 & -55.1 & -3 \\
\hline Landmark - 3 B point & 0 & -89.7 & 1.5 \\
\hline Landmark - 4 TS point & 0 & -5.2 & -58.7 \\
\hline Landmark - 5 Right $G$ point & -48.8 & -25.3 & -80.1 \\
\hline Landmark - 6 Left $G$ point & 53.2 & -24.9 & -74.2 \\
\hline Landmark - 7 Left L point & 44.1 & -60.7 & -57.6 \\
\hline Landmark - 8 Right L point & -38.6 & -61.3 & .58 .7 \\
\hline Landmark - 9 Right P point & -22.2 & -54.2 & -48.2 \\
\hline Landmark - 10 Left P point & 23.6 & -52.8 & -48 \\
\hline 2-Pt Distance $\mathrm{mm}-(\mathrm{N}$ to $\mathrm{Ts})$ & & & 58.6 \\
\hline 3-Pt Angle - - 1 & & & -4.1 \\
\hline
\end{tabular}

\begin{tabular}{|c|c|c|c|}
\hline Pnt 35- & $-x-$ & $--\gamma-$ & $-z-$ \\
\hline Landmark - 1 Nasion & 0 & 0.4 & -0.9 \\
\hline Landmark - 2 A point & 0 & -68 & 2 \\
\hline Landmark - 3 B point & 0 & -103.8 & -5.7 \\
\hline Landmark - 4 TS point & 0 & -8.6 & -64 \\
\hline Landmark - 5 Right G point & -57.8 & -31.8 & -79.3 \\
\hline Landmark - 6 Left $G$ point & 51.7 & -33.1 & -83 \\
\hline Landmark -7 Left L point & 42.1 & -71.3 & -68.6 \\
\hline Landmark - 8 Right L point & -45.3 & -70.9 & -66.4 \\
\hline Landmark - 9 Right P point & -26.6 & -64.4 & -50.5 \\
\hline Landmark - 10 Left P point & 21.4 & -65.5 & -49.7 \\
\hline 2-Pt Distance $\mathrm{mm}$ - (N to Ts) & & & 63.7 \\
\hline 3-Pt Angle $2-1$ & & & 5.1 \\
\hline Pnt 36- & $-x-$ & $-Y-$ & $-z-$ \\
\hline Landmark - 1 Nasion & 0 & 0 & 0 \\
\hline Landmark - 2 A point & 0 & -58.1 & 1.2 \\
\hline Landmark - 3 B point & 0 & $-94,9$ & 3.9 \\
\hline Landmark - 4 TS point & -0.7 & -11.3 & -63.3 \\
\hline Landmark - 5 Right G point & -48.9 & -27.6 & -82.1 \\
\hline Landmark - 6 Left $G$ point & 47.9 & -28.9 & -82.5 \\
\hline Landmark - 7 Left L point & 41.5 & -69.1 & -61.5 \\
\hline Landmark - 8 Right L point & -43.7 & -67.1 & -60.9 \\
\hline Landmark - 9 Right P point & -24.3 & -59.3 & -51.1 \\
\hline Landmark - 10 Left P point & 22.8 & -58.5 & -51.1 \\
\hline 2-Pt Distance $\mathrm{mm}$ - ( $\mathrm{N}$ to Ts) & & & 63.9 \\
\hline 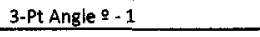 & & & -1.5 \\
\hline Pnt 37- & $-x-$ & $-\mathrm{Y}_{-}$ & $-\mathrm{z}--$ \\
\hline Landmark - 1 Nasion & 0 & -0.3 & 0 \\
\hline Landmark - 2 A point & 0 & -58.9 & 7.4 \\
\hline Landmark - 3 B point & 0 & -98.6 & 4.9 \\
\hline Landmark - 4 TS point & 0 & -9.9 & -66.3 \\
\hline Landmark - 5 Right G point & -53.3 & -29.4 & -78 \\
\hline Landmark - 6 Left $G$ point & 49.2 & -27.6 & -77.1 \\
\hline Landmark - 7 Left Lpoint & 41 & -64.5 & -60.9 \\
\hline Landmark - 8 Right L point & -43.8 & -64.2 & -60.6 \\
\hline Landmark - 9 Right $P$ point & -21.1 & -62.5 & -50 \\
\hline Landmark - 10 Left $P$ point & 21.5 & -62.5 & -49.7 \\
\hline 2-Pt Distance $\mathrm{mm}$ - (N to Ts) & & & 67 \\
\hline 3-Pt Angle $:-1$ & & & 4.5 \\
\hline Pnt 38- & $-x-$ & $-Y-$ & $-2--$ \\
\hline Landmark - 1 Nasion & 0 & 0.1 & 0 \\
\hline Landmark - 2 A point & 0 & -55.1 & 0.3 \\
\hline Landmark - 3 B point & 0 & -87.7 & 3.2 \\
\hline Landmark - 4 TS point & 0 & -5.1 & -61.8 \\
\hline Landmark - 5 Right $G$ point & -49.2 & -26.9 & -75.2 \\
\hline Landmark - 6 Left G point & 46.8 & -27.3 & -75.2 \\
\hline Landmark - 7 Left L point & 36.3 & -62.2 & -60.7 \\
\hline Landmark - 8 Right L point & -39.9 & -63.9 & -60.5 \\
\hline Landmark - 9 Right P point & -20.7 & -58.2 & -48.3 \\
\hline Landmark - 10 Left P point & 17.6 & -58.2 & -48.1 \\
\hline 2-Pt Distance $\mathrm{mm}$ - (N to Ts) & & & 62.2 \\
\hline 3-Pt Angle $:-1$ & & & -1.7 \\
\hline Pnt 39- & $--x-$ & $-Y-$ & $--Z--$ \\
\hline Landmark - 1 Nasion & 0 & -0.1 & -0.1 \\
\hline Landmark - 2 A point & -1.8 & -55.3 & 9.3 \\
\hline Landmark - 3 B point & -1.8 & -96.6 & 0.1 \\
\hline Landmark - 4 TS point & -1.8 & -14.1 & -53.7 \\
\hline Landmark - 5 Right G point & -46.9 & -31.8 & -70.7 \\
\hline Landmark - 6 Left $G$ point & 43.3 & -31.8 & -68.9 \\
\hline Landmark - 7 Left L point & 31.6 & -64.6 & -57.3 \\
\hline Landmark - 8 Right L point & -33.6 & -65.5 & -58.8 \\
\hline Landmark - 9 Right P point & -18.9 & -56.5 & -41 \\
\hline Landmark - 10 Left P point & 14.8 & -56.5 & -40.2 \\
\hline 2-Pt Distance $\mathrm{mm}-(\mathrm{N}$ to $\mathrm{Ts})$ & & & 55.1 \\
\hline 3-Pt Angle $:-1$ & & & 9.7 \\
\hline
\end{tabular}




\section{Appendix A (cont.)}

\begin{tabular}{|l|r|r|r|}
\hline Pnt 20- & \multicolumn{1}{|c|}{$X-$} & \multicolumn{1}{|c|}{$Y--$} & \multicolumn{1}{|c|}{$-Z-$} \\
\hline Landmark - 1 Nasion & 0 & 0.5 & -0.2 \\
\hline Landmark - 2 A point & 0 & -55.9 & 3.6 \\
\hline Landmark - 3 B point & 0 & -89.3 & 0.7 \\
\hline Landmark -4 TS point & 0 & -8.1 & -55.8 \\
\hline Landmark - 5 Right G point & -48 & -25.2 & -68.5 \\
\hline Landmark - 6 Left G point & 46.7 & -25.8 & -72.9 \\
\hline Landmark - 7 Left L point & 36.9 & -59.8 & -57.9 \\
\hline Landmark - 8 Right L point & -38.7 & -60.6 & -53.6 \\
\hline Landmark -9 Right P point & -19.4 & -58.1 & -43.6 \\
\hline Landmark - 10 Left P point & 19 & -58.1 & -45.9 \\
\hline 2-Pt Distance mm - (N to Ts) & & & 55.9 \\
\hline 3-Pt Angle @- 1 & & & 3 \\
\hline
\end{tabular}

\begin{tabular}{|l|r|r|r|}
\hline Pnt 40- & $-X-$ & \multicolumn{1}{|c|}{$-Y--$} & \multicolumn{1}{|c|}{-} \\
\hline Landmark - 1 Nasion & 0 & 0 & 0 \\
\hline Landmark - 2 A point & 0 & -54.8 & -4.4 \\
\hline Landmark - 3 B point & 0 & -94.8 & -17.5 \\
\hline Landmark -4 TS point & 0 & -3.2 & -62.9 \\
\hline Landmark - 5 Right G point & -52.3 & -22.4 & -73.8 \\
\hline Landmark - 6 Left G point & 46.1 & -26.1 & -72.6 \\
\hline Landmark - 7 Left L point & 39.2 & -52.5 & -59 \\
\hline Landmark - 8 Right L point & -41.3 & -56.8 & -63.8 \\
\hline Landmark - 9 Right P point & -20.8 & -51.4 & -49.8 \\
\hline Landmark - 10 Left P point & 17.8 & -51.4 & -48.6 \\
\hline 2-Pt Distance mm - (N to Ts) & & & 62.6 \\
\hline 3-Pt Angle 9-1 & & & 5.7 \\
\hline
\end{tabular}


Appendix B - Landmark accuracy test data

\begin{tabular}{|c|c|c|c|c|c|c|}
\hline & $\begin{array}{l}\text { 1st } \\
\text { run- } X\end{array}$ & $\begin{array}{l}\text { 2nd } \\
\text { run- } X\end{array}$ & $\begin{array}{l}\text { 1st } \\
\text { run-Y }\end{array}$ & $\begin{array}{l}\text { 2nd } \\
\text { run-Y }\end{array}$ & $\begin{array}{l}\text { 1st } \\
\text { run-Z }\end{array}$ & $\begin{array}{l}\text { 2nd } \\
\text { run- } Z\end{array}$ \\
\hline fubject R1-landmark 1 & -1.1 & 0 & 1.3 & 0 & 0.8 & 0.2 \\
\hline ubject R2-Landmark 1 & -0.6 & 0 & 0.4 & 0.1 & -0.3 & -0.3 \\
\hline ubject R3-Landmark 1 & -1.4 & 0 & -0.6 & 0.1 & -0.2 & 0 \\
\hline ubject R4-Landmark 1 & 0 & 0 & 0.1 & 0 & 0 & 0 \\
\hline ubject R5-Landmark 1 & 0 & 0 & 0.1 & 0.7 & -0.2 & -0.1 \\
\hline ubject R6-Landmark 1 & 0 & 0 & 0.6 & 0.1 & -0.1 & 0.1 \\
\hline ubject R7-Landmark 1 & 0 & 0 & -0.9 & -0.5 & 0 & 0.2 \\
\hline ubject R8-Landmark 1 & 0 & 0 & 0.1 & 0.1 & 0 & 0.1 \\
\hline ubject R9-Landmark 1 & 0 & 0 & -0.1 & 0 & -0.1 & -0.3 \\
\hline ubject R10-Landmark 1 & 0 & 0 & 0 & 0.1 & 0 & -0.1 \\
\hline ubject R1-landmark 2 & 0.3 & 0 & -60.9 & -60.8 & 2.3 & 2.2 \\
\hline ubject R2-Landmark 2 & -0.6 & 0 & -54.5 & -55.8 & 5.5 & 5.6 \\
\hline ubject R3-Landmark 2 & -0.3 & 0 & -56.5 & -55.5 & -0.6 & -0.7 \\
\hline ubject R4-Landmark 2 & 0 & 0 & -54.9 & -55.5 & 1.5 & 1.2 \\
\hline ubject R5-Landmark 2 & 0 & 0 & -69 & -66.7 & -1.1 & -1.6 \\
\hline ubject R6-Landmark 2 & 0 & 0 & -65 & -65.1 & -1 & -1.2 \\
\hline ubject R7-Landmark 2 & 0 & 0 & -53 & -53.8 & 2.5 & 2.6 \\
\hline ubject R8-Landmark 2 & 0 & 0 & -55.1 & -53.5 & 0.3 & -0.3 \\
\hline ubject R9-Landmark 2 & -1.8 & 0 & -55.3 & -55.2 & 9.3 & 8.8 \\
\hline ubject R10-Landmark 2 & 0 & 0 & -54.8 & -54.5 & -4.4 & -4.3 \\
\hline ubject R1-landmark 3 & 0.3 & 0 & -105.3 & -104.1 & -3.8 & -3.5 \\
\hline ubject R2-Landmark 3 & -0.6 & -0.3 & -116 & -108.2 & 8.2 & 9.3 \\
\hline ubject R3-Landmark 3 & -0.7 & 0 & -86 & -86.1 & -1.9 & -1.6 \\
\hline ubject R4-Landmark 3 & 0 & 0 & -94.6 & -93.3 & -3.5 & -3.3 \\
\hline ubject R5-Landmark 3 & 0 & 0 & -110.7 & -113.5 & -4.4 & -4.5 \\
\hline ubject R6-Landmark 3 & 0 & 0 & -109.7 & -111.5 & -20.1 & -20.8 \\
\hline ubject R7-Landmark 3 & 0 & 0 & -96.4 & -96.5 & 6 & 5.9 \\
\hline ubject R8-Landmark 3 & 0 & 0 & -87.7 & -87.8 & 3.2 & 3.3 \\
\hline ubject R9-Łandmark 3 & -1.8 & 0 & -96.6 & -97.1 & 0.1 & 0.3 \\
\hline ubject R10-Landmark 3 & 0 & 0 & -94.8 & -98.1 & -17.5 & -18.5 \\
\hline ubject R1-landmark 4 & -0.1 & 0 & -5.9 & -6.5 & -66.1 & -66.4 \\
\hline ubject R2-Landmark 4 & -0.6 & -0.3 & -8 & -8 & -67.7 & -67.9 \\
\hline ubject R3-Landmark 4 & -1.8 & 0 & -1.8 & -1.6 & -68.6 & -69.4 \\
\hline ubject R4-Landmark 4 & 0 & 0 & -7.2 & -7 & -62.2 & -62.2 \\
\hline ubject R5-Landmark 4 & 0 & 0 & -11.2 & -11.1 & -65.3 & -65.7 \\
\hline ubject R6-Landmark 4 & -1.2 & 0 & -9.5 & -10.3 & -63.7 & -64.3 \\
\hline ubject R7-Landmark 4 & 0 & 0 & -6.5 & -6.8 & -66.1 & -66.1 \\
\hline ubject R8-Landmark 4 & 0 & 0 & -5.1 & -5.6 & -61.8 & -62 \\
\hline ubject R9-Landmark 4 & -1.8 & 0 & -14.1 & -13.8 & -53.7 & -53.8 \\
\hline ubject R10-Landmark 4 & 0 & 0 & -3.2 & -3.3 & -62.9 & -63 \\
\hline ubject R1-landmark 5 & -50.6 & -51.6 & -25 & -25.6 & -76.6 & -76.6 \\
\hline ubject R2-Landmark 5 & -52.3 & -52.7 & -32.7 & -31.7 & -87.8 & -87.8 \\
\hline ubject R3-Landmark 5 & -50.3 & -50.6 & -21.2 & -21.1 & -81 & -81.3 \\
\hline ubject R4-Landmark 5 & -45.6 & -45 & -27.4 & -27.3 & -73.9 & -74 \\
\hline ubject R5-Landmark 5 & -50.1 & -50.2 & -29.8 & -30 & -80.4 & -81.7 \\
\hline ubject R6-Landmark 5 & -49.5 & -49.9 & -30 & -29.8 & -86.4 & -86.8 \\
\hline ubject R7-Landmark 5 & -50.2 & -49.2 & -27.3 & -27.3 & -78.4 & -79 \\
\hline ubject R8-Landmark 5 & -49.2 & -49.2 & -26.9 & -26.8 & -75.2 & -75 \\
\hline ubject R9-Landmark 5 & -46.9 & -46.4 & -31.8 & -31.7 & -70.7 & -70.6 \\
\hline Subject R10-Landmark 5 & -52.3 & -52.2 & -22.4 & -22.5 & -73.8 & -73.5 \\
\hline
\end{tabular}


Appendix B - Landmark accuracy test data

\begin{tabular}{|c|c|c|c|c|c|c|}
\hline & $\begin{array}{l}\text { 1st } \\
\text { run-X }\end{array}$ & $\begin{array}{l}\text { 2nd } \\
\text { run- } x\end{array}$ & $\begin{array}{l}1 \text { st } \\
\text { run-Y }\end{array}$ & $\begin{array}{l}\text { 2nd } \\
\text { run-Y }\end{array}$ & $\begin{array}{l}\text { Ist } \\
\text { run-Z }\end{array}$ & $\begin{array}{l}\text { 2nd } \\
\text { run-Z }\end{array}$ \\
\hline Subject R1-landmark 6 & 49.6 & 49.3 & -24.7 & -25.4 & -81.1 & -80.8 \\
\hline Subject R2-Landmark 6 & 50.1 & 49.9 & -31.5 & -31.1 & .88 .9 & -89.7 \\
\hline Subject R3-Landmark 6 & 45.2 & 46.8 & -20.7 & -20.5 & -85.3 & -84.9 \\
\hline Subject R4-Landmark 6 & 43.3 & 43.4 & -24.8 & -24.5 & -76.9 & -77 \\
\hline Subject R5-Landmark 6 & 49.3 & 49.9 & -31 & -31.2 & -82.8 & -83 \\
\hline Subject R6-Landmark 6 & 50.5 & 50.1 & -28.2 & -28.2 & -80.8 & -81.1 \\
\hline Subject R7-Landmark 6 & 49.5 & 49.3 & -26.1 & -25.6 & -77.6 & -77.8 \\
\hline Subject R8-Landmark 6 & 46.8 & 46.6 & -27.3 & -27.6 & -75.2 & -75 \\
\hline Subject R9-Landmark 6 & 43.3 & 43.5 & -31.8 & -32.1 & -68.9 & -68.5 \\
\hline Subject R10-Landmark 6 & 46.1 & 46 & -26.1 & -25.8 & -72.6 & -72.7 \\
\hline Subject R1-landmark 7 & 42.1 & 42.1 & -64.6 & -62.7 & -64.9 & -64.3 \\
\hline Subject R2-Landmark 7 & 41.5 & 41.8 & -72 & -72.2 & -66.6 & -66.3 \\
\hline Subject R3-Landmark 7 & 38.7 & 39.3 & -60.3 & -61.5 & -64.6 & -65.1 \\
\hline Subject R4-Landmark 7 & 34.8 & 35.2 & -59.8 & -59.6 & -61.8 & -62.2 \\
\hline Subject R5-Landmark 7 & 41.9 & 41.4 & -69.1 & -68.6 & -66.9 & -66.3 \\
\hline Subject R6-Landmark 7 & 40.5 & 40.2 & -66.2 & -66.2 & -70.4 & -70.2 \\
\hline Subject R7-Landmark 7 & 40.8 & 40.8 & -63.1 & -62.9 & -59.6 & -59.5 \\
\hline Subject R8-Landmark 7 & 36.3 & 36.6 & -62.2 & -62.5 & -60.7 & -60.9 \\
\hline Subject R9-Landmark 7 & 31.6 & 31.2 & -64.6 & -64.7 & -57.3 & -56.6 \\
\hline Subject R10-Landmark 7 & 39.2 & 39 & -52.5 & -52.4 & -59 & -58.7 \\
\hline Subject R1-landmark 8 & -43.3 & -43.9 & -65.1 & -64.5 & -62.2 & -62.1 \\
\hline Subject R2-Landmark 8 & -44.6 & -44.1 & -70 & -71.1 & -65.5 & -65.6 \\
\hline Subject R3-Landmark 8 & -41.9 & -42.6 & -61.8 & -62 & -63.4 & -63.5 \\
\hline Subject R4-Landmark 8 & -35.1 & -35.3 & -60.7 & -61 & -62.3 & -62.2 \\
\hline Subject R5-Landmark 8 & -41.4 & -42.3 & -71.4 & -67.9 & -64.4 & -65 \\
\hline Subject R6-Landmark 8 & -39.7 & -40.1 & -66.4 & -63.5 & -71 & -70.6 \\
\hline Subject R7-Landmark 8 & -42.3 & -42.4 & -62.9 & -60.9 & -60.2 & -59.6 \\
\hline Subject R8-Landmark 8 & -39.9 & -39.7 & -63.9 & -63.9 & -60.5 & -60.4 \\
\hline Subject R9-Landmark 8 & -33.6 & -33.5 & -65.5 & -65.4 & -58.8 & -58.5 \\
\hline Subject R10-Landmark 8 & -41.3 & -41.6 & -56.8 & -56.8 & -63.8 & -63.9 \\
\hline Subject R1-landmark 9 & -21 & -21.2 & -60.3 & -60.8 & -51.7 & -51.9 \\
\hline Subject R2-Landmark 9 & -26 & -25.8 & -66.3 & -66.6 & -48.1 & -48.5 \\
\hline Subject R3-Landmark 9 & -23.5 & -26.2 & -56.7 & -55.4 & -53.9 & -54.6 \\
\hline Subject R4-Landmark 9 & -19.3 & -20.1 & -55.1 & -55.4 & -46.9 & -47.5 \\
\hline Subject R5-Landmark 9 & -22.5 & -23 & -62.8 & -63.5 & -55 & -54.5 \\
\hline Subject R6-Landmark 9 & -17.7 & -20 & -61.9 & -62.6 & -52.4 & -52 \\
\hline Subject R7-Landmark 9 & -21.2 & -20.4 & -58.7 & -59.1 & -50.9 & -49.6 \\
\hline Subject R8-Landmark 9 & -20.7 & -20.9 & -58.2 & -57.7 & -48.3 & -48.1 \\
\hline Subject R9-Landmark 9 & -18.9 & -18.9 & -56.5 & -56.6 & -41 & -40.9 \\
\hline Subject R10-Landmark 9 & -20.8 & -21.1 & -51.4 & -51.6 & -49.8 & -50.1 \\
\hline Subject R1-landmark 10 & 22.6 & 22.3 & -60.3 & -60.8 & -52.7 & -52.7 \\
\hline Subject R2-Landmark 10 & 23.2 & 23.2 & -66.3 & -66.5 & -47.8 & -47.5 \\
\hline Subject R3-Landmark 10 & 21.6 & 23.4 & -55.3 & -53.8 & -54.2 & -54.9 \\
\hline Subject R4-Landmark 10 & 19.5 & 20.4 & -55.1 & -55.4 & -47.1 & -48.1 \\
\hline Subject R5-Landmark 10 & 22.4 & 22.3 & -63.5 & -63.5 & -56.4 & -55.7 \\
\hline Subject R6-Landmark 10 & 18.9 & 19.3 & -61.3 & -62.2 & -53 & -50 \\
\hline Subject R7-Landmark 10 & 20.7 & 19.5 & -58.7 & -59.1 & -50.7 & -49.3 \\
\hline Subject R8-Landmark 10 & 17.6 & 17.6 & -58.2 & -57.7 & -48.1 & -48.8 \\
\hline Subject R9-Landmark 10 & 14.8 & 15.2 & -56.5 & -56.6 & -40.2 & -40.3 \\
\hline Subject R10-Landmark 10 & 17.8 & 17.7 & -51.4 & -51.6 & -48.6 & -48.9 \\
\hline
\end{tabular}




\section{CURRICULUM VITAE}

\section{CPT Russell M. Weaver}

216 Brunswick Rd.

Louisville KY, 40207

(910) 603-7522

\section{Personal information:}

Date of Birth: Place of Birth:

Marital Status:

Citizenship:

\section{Education:}

2008- Present

2004-2005

2000-2004

$1997-2000$

\author{
June 20, 1973 \\ Ft. Sill, Oklahoma \\ Married
}

Orthodontic residency training

University of Louisville, School of Dentistry

Degree: Masters in Oral Biology, Certificate in Orthodontics

Graduation: June 2010

U.S. Army, Advanced General Dentistry Residency (AGD-12), Ft. Lewis, WA

Graduation: October 2005

Virginia Commonwealth University School of Dentistry, Richmond, VA Degree: DDS, Magna cum Laude Date of Degree: May 2004

The College of William and Mary, Williamsburg, VA Degree: Bachelor of Science, Cum Laude Major: Biology Minor: Military Science Dater of Degree: May 2000

Naval School of Health Sciences Naval Medical Center, Portsmouth, VA Degree: Surgical Technologist

Date of Degree: September 1995 
Naval Hospital Corps School

Great Lakes, $\mathrm{IL}$

Degree: Naval Hospital Corpsman

Date of Degree: July 1992

\section{Military Training:}

April 2007

March 2006

November 2005

January 2005

June 2001

$1998-2000$

Army Pathfinder School, Miami, Fl.

Expert field medical badge (EFMB) course, Ft. Indian Town Gap, PA

Army Airborne School, Ft. Benning, GA

U.S. Army Combat Casualty Care Course (C-4)

AMEDD Officer Basic Course (OBC), Ft. Sam Houston, TX

Reserve Officer Training Corps. (ROTC), Revolutionary Guard Battalion, College of William \& Mary

\section{Honors and Awards:}

2008

2008

2004

2004

$2001-2004$

2002

2001

$2000-2004$

\section{Employment:}

2004-Present

June 2004

Bronze Star Medal, Kandahar, Afghanistan

Combat Medical Badge, Kandahar, Afghanistan

Omicron Kappa Upsilon: National Dental Honor Society

Phi Kappa Phi Honor Society: Virginia Commonwealth University

Virginia Commonwealth University, School of Dentistry Scholarship

International College of Dentists Scholarship, Virginia Section

A.D. Williams Academic Achievement Scholarship

Dean's List: Virginia Commonwealth University School of Dentistry

Part-time undergraduate dental clinic faculty 
Virginia Commonwealth University School of Dentistry

2003-2004

Teaching Assistant / Tutor

Virginia Commonwealth University School of Dentistry

1992-1997

United States Navy, Hospital Corpsman, Surgical Technologist 